\title{
IITLE PAGE
}

Title

Switch to natalizumab vs fingolimod in active relapsing-remitting multiple sclerosis

\section{Running head}

Natalizumab vs fingolimod in active MS

\section{Authors}

Tomas Kalincik, MD, PhD, PGCertBiostat ${ }^{1,2}$; Dana Horakova, MD, PhD ${ }^{3}$; Timothy Spelman, MBBS, MSc, GCertStat ${ }^{1,2}$; Vilija Jokubaitis, $\mathrm{PhD}^{1}$; Maria Trojano, $\mathrm{MD}^{4}$; Alessandra Lugaresi, $\mathrm{MD}^{5}$; Guillermo Izquierdo, $\mathrm{MD}^{6}$; Csilla Rozsa, $\mathrm{MD}^{7}$; Pierre Grammond, $\mathrm{MD}^{8}$; Raed Alroughani, MD, $\mathrm{PhD}^{9}$; Pierre Duquette, $\mathrm{MD}^{10}$; Marc Girard, MD ${ }^{10}$; Eugenio Pucci, $\mathrm{MD}, \mathrm{PhD}^{11}$; Jeannette Lechner-Scott, MD ${ }^{12}$; Mark Slee, $\mathrm{MBBS}^{13}$; Ricardo Fernandez-Bolanos, MD ${ }^{14}$; Francois Grand'Maison, MD ${ }^{15}$;

Raymond Hupperts, $\mathrm{MD}^{16}$; Freek Verheul, $\mathrm{MD}^{17}$; Suzanne Hodgkinson, MD, PhD ${ }^{18}$; Celia Oreja-Guevara, $\mathrm{MD}^{19}$; Daniele Spitaleri, $\mathrm{MD}^{20}$; Michael Barnett, MD, $\mathrm{PhD}^{21}$; Murat Terzi, $\mathrm{MD}^{22}$; Roberto Bergamaschi, MD ${ }^{23}$; Pamela McCombe, $\mathrm{MD}^{24}$; Jose Sanchez-Menoyo, MD ${ }^{25}$; Magdolna Simo, MD ${ }^{26}$; Tunde Csepany, MD ${ }^{27}$; Gabor Rum, MD ${ }^{28}$; Cavit Boz, MD ${ }^{29}$; Eva Havrdova, $\mathrm{MD}, \mathrm{PhD}^{3}$; Helmut Butzkueven, MBBS, $\mathrm{PhD}^{1,2,30} *$

on behalf of the MSBase Study Group ${ }^{+}$

*These authors contributed equally to the manuscript.

+Contributing members of the MSBase Study Group are listed in Supplementary Table 1.

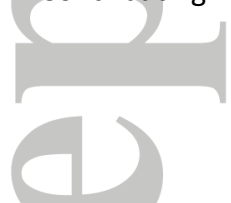

\section{Affiliations}

${ }^{1}$ Department of Medicine, University of Melbourne, Grattan St, Melbourne, VIC 3052, Australia

${ }^{2}$ Department of Neurology, Royal Melbourne Hospital, Grattan St, Melbourne, VIC 3052, Australia

${ }^{3}$ Department of Neurology and Center of Clinical Neuroscience, 1st Faculty of Medicine, General University Hospital and Charles University in Prague, Katerinska 32, Praha, 12800, Czech Republic

${ }^{4}$ Department of Basic Medical Sciences, Neuroscience and Sense Organs, University of Bari, Via Calefati 53, Bari, 70122, Italy

This article has been accepted for publication and undergone full peer review but has not been through the copyediting, typesetting, pagination and proofreading process which may lead to differences between this version and the Version of Record. Please cite this article as an 'Accepted Article', doi: 10.1002/ana.24339

This article is protected by copyright. All rights reserved. 
${ }^{5}$ Department of Neuroscience and Imaging, University 'G. d'Annunzio', Via dei Vestini, Chieti, 66100, Italy

${ }^{6}$ Hospital Universitario Virgen Macarena, Amador de los Rios 48-50 4a, Sevilla, 41003, Spain

7 Jahn Ferenc Teaching Hospital, Koves u. 1, Budapest, 1204, Hungary

${ }^{8}$ Hotel-Dieu de Levis, 9500 blvd Centre-Hospitalier, Quebec, G6X0A1, Canada

${ }^{9}$ Department of Neurology, Amiri Hospital, P.O. Box 1661, Qurtoba, Kuwait City, Kuwait

${ }^{10}$ Hôpital Notre Dame, 1560 Sherbrooke East, Montreal, H2L4M1, Canada

${ }^{11}$ Ospedale di Macerata, via Santa Lucia, Macerata, 62100, Italy

12 John Hunter Hospital, Lookout Road, Newcastle, NSW 2305, Australia

${ }^{13}$ Flinders University and Medical Centre, Flinders Drive, Adelaide, 5042, Australia

${ }^{14}$ Hospital Universitario Virgen de Valme, Crta. Cádiz, s/n, Seville, 41014, Spain

${ }^{15}$ Neuro Rive-Sud, Hôpital Charles LeMoyne, 4896 boul. Taschereau, suite 250, Quebec, J4V2J2, Canada

${ }^{16}$ Orbis Medical Center, Walramstraat 23, Sittard, 6131BK, The Netherlands

${ }^{17}$ Groen Hart Ziekenhuis, Bleulandweg 10, Gouda, 2800BB, The Netherlands

${ }^{18}$ Liverpool Hospital, Neurology Department, Elizabeth St, Liverpool, 2170, Sydney, Australia

${ }^{19}$ University Hospital San Carlos, IdISSC, Paseo de la Castellana 261, Madrid, 28050, Spain

${ }^{20}$ AORN San Giuseppe Moscati, Contrada Amoretta, Avellino, 83100, Italy

${ }^{21}$ Brain and Mind Research Institute, University of Sydney, 100 Mallett, Sydney, NSW 2050, Australia

${ }^{22}$ Medical Faculty, Department of Neurology, 19. Mayis University, Kurupelit, Samsun, 55160, Turkey

${ }^{23}$ National Neurological Institute C. Mondino, via Mondino 2, Pavia, 27100, Italy

${ }^{24}$ Department of Neurology, Royal Brisbane and Women's Hospital, Herston, 4029, Brisbane, Australia

${ }^{25}$ Department of Neurology, Hospital de Galdakao-Usansolo, Barrio Labeaga s.n. Galdakao, 48660, Spain

${ }^{26}$ Semmelweis University, Ulloi u. 26, 1085, Budapest, Hungary

${ }^{27}$ Department of Neurology, University of Debrecen, Moricz Zs. krt 22, Debrecen, 4032, Hungary

${ }^{28}$ Department of Neurology, Petz A. County Hospital, Vasvari P. u. 2-4, Gyor, 9024, Hungary

${ }^{29}$ Karadeniz Technical University, Trabzon, 61080, Turkey

${ }^{30}$ Box Hill Hospital, Monash University, Nelson Rd, Box Hill, VIC 3128, Australia

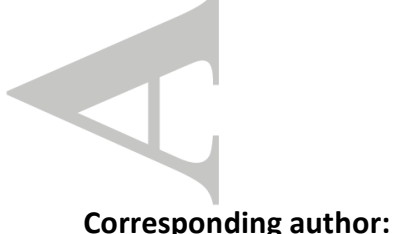

Tomas Kalincik 
L4 Centre, Melbourne Brain Centre at Royal Melbourne Hospital

Grattan St

Parkville VIC 3050

Australia

Tel: +61393424404

Fax: +61393495997

Fax: +61393

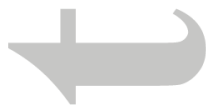

Character count: Title 84, Running Head 38

Abstract word count: 246

Manuscript word count: 3723 (Introduction 287, Discussion 1097)

Figures: 5

Colour figures: 3

Tables: 3
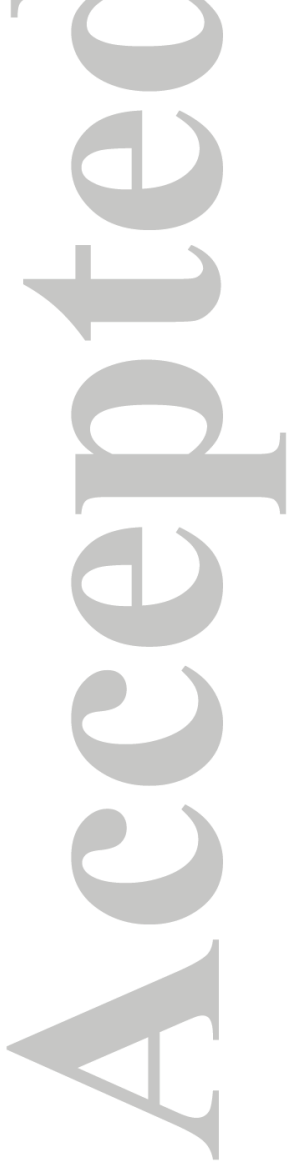


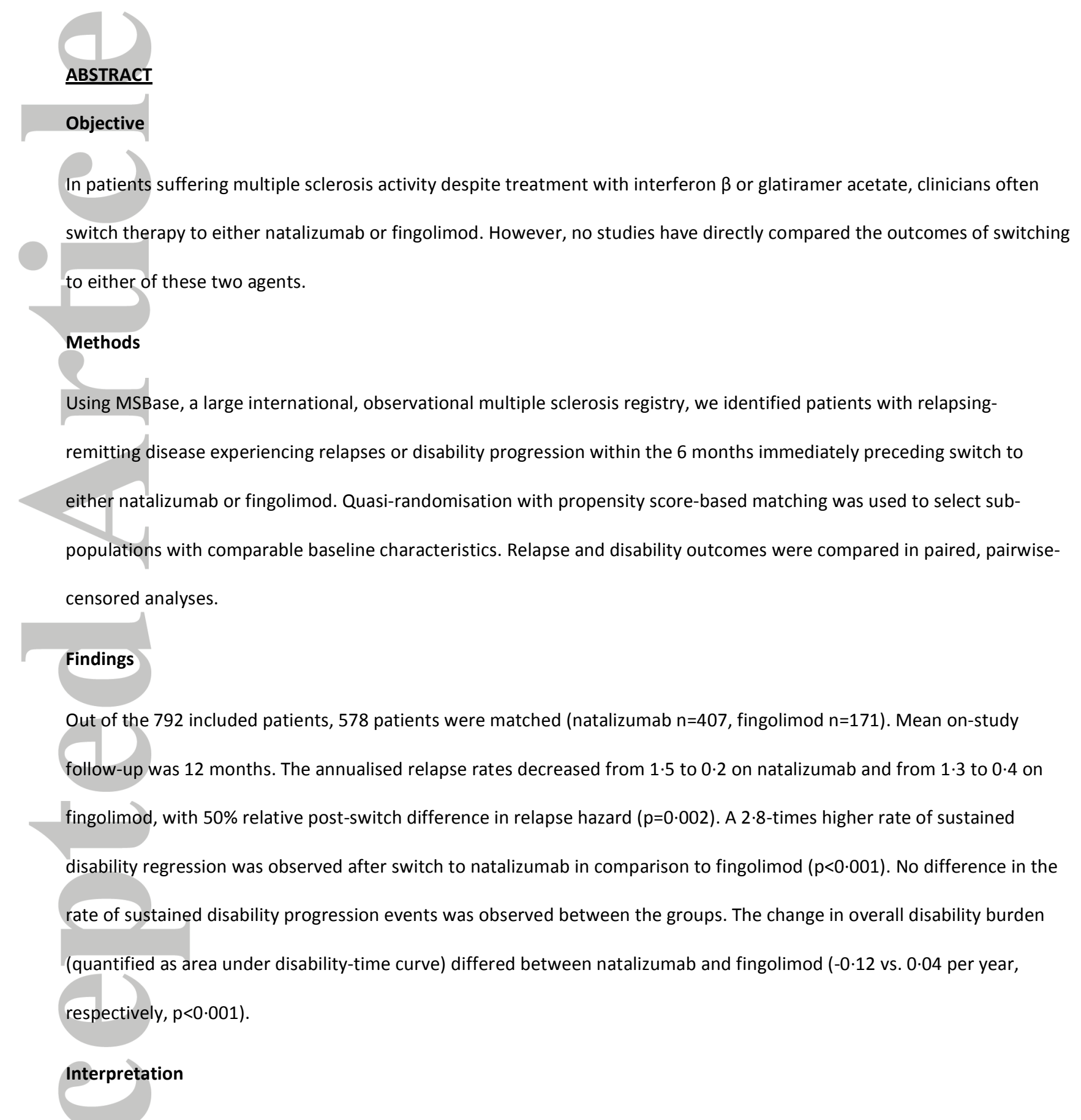

This study suggests that in active multiple sclerosis during treatment with injectable disease modifying therapies, switch to natalizumab is more effective than switch to fingolimod in reducing relapse rate and short-term disability burden.

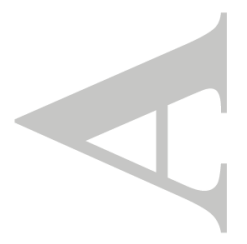




\section{INTRODUCTION}

Injectable disease modifying therapies (DMTs; interferon $\beta$ or glatiramer acetate) significantly reduce relapse rate and short-term disability progression in multiple sclerosis (MS).$^{1-6}$ However, a substantial number of treated patients continue to experience disease activity. The risks are $55-80 \%$ for relapses and $33-46 \%$ for progression of disability while on injectable DMT over 2 years. ${ }^{7}$ In order to maximise the proportion of patients free from disease activity, ${ }^{8}$ a common strategy in those with suboptimal treatment response is treatment escalation to agents with presumed higher efficacy. Natalizumab and fingolimod are two agents commonly used for treatment escalation as their efficacy is considered superior to that of the injectable DMTs. ${ }^{9,10}$ However, the evidence concerning the effect of these agents in breakthrough disease is limited. The SENTINEL trial ${ }^{10}$ demonstrated superiority of add-on of natalizumab to interferon $\beta-1$ a versus interferon $\beta$ - 1 a alone, and a subgroup analysis of the TRANSFORMS trial ${ }^{11}$ showed superior efficacy of switching to fingolimod versus interferon $\beta-1 a$ following failure of prior treatment with interferon $\beta$ or glatiramer acetate. No study has so far directly compared the efficacy of switch to fingolimod or natalizumab as treatment escalation in the setting of recent treatment failure. ${ }^{12}$

Given practical and financial limitations, it is unlikely that escalation to natalizumab or fingolimod will be directly compared in a randomised head-to-head trial. A feasible alternative strategy is to utilise existing longitudinal registries of clinical outcomes data. ${ }^{13}$ MSBase is the largest international, observational registry of MS outcomes, and we previously demonstrated its utility in the analysis of treatment outcomes using propensity-matching to mitigate potential treatment indication bias. ${ }^{14-16}$

The aim of this study was to compare the outcomes of treatment escalation to either natalizumab or fingolimod in MS patients experiencing recent disease activity on injectable DMTs.

\section{PATIENTS AND METHODS}

The MSBase registry ${ }^{17}$ (registered with WHO ICTRP, ID ACTRN12605000455662) was approved by the Melbourne Health Human Research Ethics Committee, and by the local ethics committees in all participating centres (or exemptions granted, according to local regulations). If required, written informed consent was obtained from enrolled patients.

\section{John Wiley \& Sons}

This article is protected by copyright. All rights reserved. 


\section{Database and study population}

Longitudinal data from 25,960 patients from 66 MS centres in 26 countries were extracted from the MSBase registry in December 2013. For this analysis, we selected patients with relapsing-remitting MS who had switched therapy from interferon $\beta$ or glatiramer acetate to either natalizumab or fingolimod (treatment gap < 3 months; no unified escalation protocol was used) after on-treatment relapse and/or progression of disability documented within the preceding 6 months (i.e. clinical breakthrough activity). The pre-switch disability progression was defined as increase in the Expanded Disability Status Scale (EDSS) by at least 1 step over the year immediately preceding the baseline (no EDSS scores recorded within 30 days of a clinical relapse were included). Minimum 3-month persistence on natalizumab or fingolimod was required. The minimal required dataset consisted of sex, month and year of birth, date of first MS symptoms, dates of clinical relapses, clinical MS course, disability quantified with EDSS recorded at the time of treatment escalation (i.e. the study baseline, -6 to +3 months) and at least one subsequent on-treatment visit with EDSS record. Patients previously participating in randomised trials involving studied agents or receiving teriflunomide, dimethyl fumarate, fingolimod, cladribine, mitoxantrone, natalizumab, rituximab or alemtuzumab before baseline were excluded. Patients were censored at discontinuation or change of therapy or end of follow-up (whichever occurred first). Quality assurance procedures were applied as described elsewhere. ${ }^{14,18}$

All information was recorded as part of routine clinical practice with real time or near-real time data entry in association with clinical visits. The MSBase protocol stipulates minimum annual updates of the minimum dataset, but patients with less frequent updates were not excluded. Data entry portal was either the iMed patient record system or the MSBase online data entry system.

\section{Study endpoints}

A relapse was defined as occurrence of new symptoms or exacerbation of existing symptoms persisting for at least 24 hours, in the absence of concurrent illness or fever, and occurring at least 30 days after a previous relapse. ${ }^{19}$ Confirmation of relapses by increased EDSS was not required. Disability was scored by accredited scorers using EDSS (online Neurostatus certification was required at each centre), excluding any EDSS score recorded within 30 days of a previous relapse. The

\section{John Wiley \& Sons}

This article is protected by copyright. All rights reserved. 
EDSS scores were derived from functional scores. Formal assessment of cognitive function or fatigue was not done routinely. MS duration was calculated from the first demyelinating event.

Progression of EDSS was defined as increase of $\geq 1$ EDSS step ( $\geq 1 \cdot 5$ EDSS step if baseline EDSS was 0 ) sustained for $\geq 6$ months. Regression of EDSS was defined as decrease of $\geq 1$ EDSS step (1.5 EDSS step if baseline EDSS was 1.5$)$ sustained for $\geq 6$ months. Burden of disability over the follow-up period was quantified as the area under EDSS-time curve (AUC). The AUC was previously validated as a sensitive summative metric of all disability (transient as well as permanent) experienced by a patient during a follow-up period, with effective use of serial data. ${ }^{20,21}$ The AUC change was calculated relative to the baseline EDSS, between the baseline and a censoring event using the trapezium rule. ${ }^{20}$ Median EDSS at 6-12, 12-18 and $18-$ 24 months post-escalation was calculated for patients with available information.

Individual annualised relapse rate (ARR) was calculated as the annualised number of recorded relapses between baseline and a censoring event. Semi-annual relapse rate was also evaluated at 0-6, 6-12, 12-18 and 18-24 months post-baseline.

Where available, categorised evaluations of MRI (within the year preceding baseline) and cerebrospinal fluid (at any timepoint) were reported by the treating neurologists. The availability of MRI data was higher in the natalizumab than fingolimod switch group (Table 1). The proportion of patients with 1-8 lesions was relatively lower in the fingolimod group. However, the difference in proportion of patients with nine or more lesions was small. The observed differences in contrast-enhancing lesion counts and cerebrospinal fluid analysis were only marginal. Due to the high proportion of missing data, the categorised MRI data were not included in the propensity matching, but were adjusted for in all analyses.

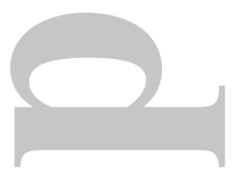

\section{Matching and statistical analysis}

Matching and statistical analysis was conducted by TK using R (version $3 \cdot 0 \cdot 2) .^{22}$ The included patients were matched on their propensity of receiving natalizumab or fingolimod using Matchlt package. ${ }^{23}$ The propensity score was based on a multivariable logistic regression model with treatment allocation as the outcome variable and the demographic and clinical variables available to treating neurologists at the time of the treatment assignation as the independent variables. These comprised sex, age and disease duration at baseline, EDSS, number of relapses in the 6 or 12 months pre-baseline, evidence of on-treatment MS activity (relapse, progression of disability or both), number of prior DMTs, the DMT used immediately before escalation and country. Given that the baseline MRI information was incomplete (at the time of the treatment decision), this was not included in the propensity-matching procedure but instead it was used to adjust the subsequent 
analyses. The missing values of the T2 lesion volume variable ( $55 \%$ in the matched dataset) were imputed based on a model using patient ID, sex, age at baseline, baseline date, MS duration at baseline, treatment group, baseline EDSS, pre-baseline on-treatment MS activity, the last pre-baseline DMT, time from the previous DMT and the duration of the pre-baseline

follow-up. We have used multiple imputation with an EMB algorithm (expectation-maximization with bootstrapping, Amelia package for R) to generate 5 imputed datasets. In addition, we have estimated the associations between multiple demographic and clinical variables vs. the availability of the baseline MRI variables with a multivariable logistic regression model.

The individual propensity scores were calculated as the sums of products of the covariates and their corresponding coefficients for the variables with $p \leq 0 \cdot 1$. Patients were then matched in a variable ratio of up to $6: 1$ using nearest neighbour matching within a caliper of 0.1 standard deviations of the propensity score, without replacement. All subsequent analyses were then structured as paired models with weights assigned to each pair to adjust for multiple inclusion of some patients in several pairs (with 1 being the maximum allowed cumulative weight per patient). Treatment persistence was evaluated as time to censoring/treatment discontinuation with a weighted frailty proportional hazards model (with the frailty term indicating the matched patient sets). The common (pairwise) on-treatment follow-up was determined as the shorter of the two individual follow-up periods for each matched patient pair (pairwise censoring). The purpose of the pairwise censoring was to control attrition bias. Normality of data distribution was assessed and ARR was compared with a weighted negative binomial model with cluster effect for matched patient pairs and adjusted for categorised number of hyperintense T2 lesions on the baseline MRI. Annualised changes in AUC, 6-monthly EDSS and 6monthly relapse counts were compared with weighted paired t-tests. The proportions of patients free from relapse, with 6 month sustained disability progression and with 6-month sustained disability regression were evaluated with weighted frailty proportional hazards models adjusted for categorised baseline T2 lesion number. Cumulative hazard of relapses was analysed with a weighted frailty proportional hazards model with robust estimation of variance adjusted for categorised baseline T2 lesion number. All primary analyses were also repeated without the adjustment for baseline T2 lesion number. Proportionality of hazards was assessed with Schoenfeld's global test.

Six sensitivity analyses were carried out: (i) using normalised weights to approximate the inferences in the dataset with imputed missing MRI values under Missing Not At Random mechanism ${ }^{24}$ (the $\delta$ was chosen based on the algorithm described by Heraud-Bousquet and colleagues ${ }^{25}$ ), (ii) without imputing the missing MRI values while allowing the "missing" value where the information was unavailable, including (iii) only patients with a documented relapse within the 6 months preceding treatment switch (i.e. excluding patients with disability progression only), (iv) all switching patients irrespective 
of pre-baseline disease activity, ( $v$ ) patients with baseline EDSS recorded between -50 to +7 days of study baseline (thus eliminating the immortal time bias) or (vi) adjusted for the baseline EDSS and the number of relapses within the 12 months preceding baseline but not the T2 lesion number. To evaluate robustness to non-recognised confounders of treatment assignation, Rosenbaum bounds based on Hodges-Lehmann $\Gamma$ were estimated for the analyses of ARR and AUC. ${ }^{26}$ Observed differences were considered significant if two-tailed $p \leq 0 \cdot 05$. A power analysis was conducted to define the lower bounds of the minimum effect sizes at $\alpha=0.05$ detectable in the available dataset at $1-\beta=0.8$. Series of simulations $(n=200)$ were carried out for each or the used statistical models and using the observed distributions of the outcome variables.

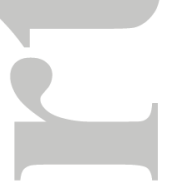

Role of the funding source

The study was conducted separately and apart from the guidance of the sponsors.

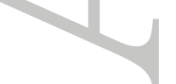

\section{RESULTS}

A total of 792 patients were included in the analysis (Figure 1, Supplementary Table 2). The median on-study follow-up was 21 months (quartiles 12-34) and 14 months (quartiles 8-20) after switching therapy to natalizumab or fingolimod, respectively. Baseline characteristics of the included patients, including previous treatment, are shown in (Table 1 and Supplementary Table 3). Several markers of disease severity differed significantly between the unmatched patient groups. The logistic model, used to estimate propensity scores, showed that higher disability, more relapses recorded within the 12 months preceding treatment escalation and country-specific practice in the Czech Republic and the Netherlands were positively associated with the probability of switching to natalizumab. In contrast, older age and country-specific practice in Spain were positively associated with switch to fingolimod (see Supplementary Table 4). The variable propensity-matching procedures retained $407(73 \%)$ and $171(74 \%)$ patients who switched to natalizumab or fingolimod, respectively. The matching procedure significantly improved the overall match, as indicated by the decrease from 0.39 to 0.01 (97\%) in the mean difference in propensity scores (see Figure 2). This was reflected by the improved match on the individual determinants of treatment allocation, including patient age, disability and the number of previously recorded relapses (Table 1). The median difference between baseline date and the date of the baseline EDSS were comparable between the matched cohorts (-83 days [quartiles -145 to -27 ] for natalizumab vs. -78 days [quartiles -132 to -15 ] for fingolimod). The 
mean on-study visit density in the matched cohorts was $2 \cdot 86 \pm 1 \cdot 78$ visits per year for the natalizumab group and $2 \cdot 87 \pm 1 \cdot 78$ visits per year for the fingolimod group (mean \pm standard deviation).

Treatment persistence following the baseline did not differ between the compared therapies, with the proportion of patients discontinuing therapy at 24 months reaching $27 \%$ and $31 \%$ in the natalizumab and fingolimod group, respectively $(p=0.9 ;$ Figure 3$)$. The proportion of relapse-free patients was higher among those switching to natalizumab than fingolimod (hazard ratio $=1 \cdot 5,95 \%$ confidence interval $1 \cdot 1-2 \cdot 2, p=0 \cdot 02$; Figure 4 ) and the cumulative hazard of relapses was relatively lower in the natalizumab group (hazard ratio=0 $6,95 \%$ confidence interval $=0 \cdot 4-0 \cdot 8, p=0 \cdot 002$ ). ARR decreased in both groups, with a more prominent drop after switch to natalizumab $(1 \cdot 5$ to $0 \cdot 2)$ compared to fingolimod $(1 \cdot 3$ to $0 \cdot 4 ; p=0 \cdot 002)$. The difference in ARR was sustained throughout the two years post-switch.

We did not observe any differences in the proportion of patients free from 6 -month sustained disability progression ( $p=0 \cdot 3$ ) or in the EDSS scores evaluated semi-annually $(3 \cdot 0-3 \cdot 5 ; p>0 \cdot 1)$. The annualised area under EDSS-time curve was lower among patients switching to natalizumab (-0.12 vs. 0.04, respectively; $p<0 \cdot 001$; Figure 5$)$. The negative area under EDSS-

time curve in the natalizumab group suggested decrease in disability. This was confirmed by the higher proportion of patients experiencing 6-month sustained regression of disability after switching to natalizumab (20\%) compared to fingolimod ( $11 \%$ at 24 months; hazard ratio=2·8, 95\% confidence interval=1·7-4·6, $p<0 \cdot 001$ ).

According to the post-hoc power analysis, the lower bounds for the detectable minimum effects were 1.49 (hazard ratio) for treatment persistence, 1.42 (hazard ratio) for the proportion of patients free from relapse, 0.09 relapse per year for ARR, 0.07 EDSS-year for AUC, $2 \cdot 2$ (hazard ratio) for the disability progression hazard and 1.65 (hazard ratio) for the disability regression probability.

John Cunningham (JC) virus status (recorded before the end of the study) was available for 140 patients treated with natalizumab. Among those who discontinued or switched treatment with natalizumab (see Supplementary Table 3), 22 patients were JC virus-positive and 11 patients were JC virus-negative. Among those who continued in treatment with natalizumab, 37 patients were JC virus-positve and 70 patients were JC virus-negative.

The primary analysis, repeated without the adjustment for baseline T2 lesion number, confirmed the outcomes of the primary analysis in full extent. The sensitivity analyses (Supplementary Table 5) replicated the outcomes of the primary analysis when the missingness of the baseline MRI variables was not assumed to be random (for the purpose of multiple imputation) and when no imputation was used and missing MRI values were allowed. The estimated associations between demographic and clinical variables vs. the availability of the baseline MRI are shown in Supplementary Table 6. Sensitivity 
analyses in subpopulations with a recent documented relapse $(n=622)$ or irrespective of their recent disease activity $(n=1084)$ also confirmed the findings of the primary analysis in full extent. The sensitivity analysis among patients with the baseline EDSS recorded between -50 to +7 days of the baseline replicated all relapse, disability and persistence outcomes of the primary analysis, with the exception of the proportion of patients free from relapses, where a non-significant trend was observed, which could be attributed to the relatively low power $(n=479)$. Finally, the sensitivity analysis adjusted for the baseline EDSS and the number of relapses within the 12 months preceding baseline validated the outcomes of the primary analysis in full. For the comparisons of ARR and AUC, the results of matching and analysis were resistant to unknown confounders with relative magnitudes of $80 \%$ and $10 \%$ of the propensity score (Hodges-Lehmann $\Gamma$ ), respectively.

\section{(

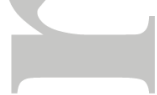 \\ DISCUSSION}

We conducted a propensity score-matched analysis of switch to either fingolimod or natalizumab after treatment failure.

The ARR was reduced from 1.5 to 0.2 after switching to natalizumab and from 1.3 to 0.4 after switching to fingolimod. The relapse rate was $50 \%$ lower after switching to natalizumab than fingolimod, with a corresponding $50 \%$ relative increase of the proportion of relapse-free patients on natalizumab. Six-month sustained disability progression rates did not differ between treatments. However, patients switching to natalizumab were $2 \cdot 8$-times more likely to experience a 6 -month sustained regression of disability than those switching to fingolimod.

Two prior phase III randomised controlled trials evaluated the efficacy of fingolimod in comparison to placebo (FREEDOMS) or interferon $\beta$ (TRANSFORMS). The FREEDOMS trial demonstrated superior efficacy of fingolimod on relapse, disability and MRI outcomes (new, enlarging or contrast-enhancing lesions), including 30\% reduction of brain atrophy over 24 months. ${ }^{27}$ The 12-month TRANSFORMS trial showed superior effect of fingolimod on relapse activity and MRI outcomes compared to intramuscular interferon $\beta-1 a{ }^{9}$ This observation was confirmed in a 12-month trial extension, when the patients originally randomised to interferon $\beta$ experienced drop in relapse and MRI activity after re-allocation to fingolimod. ${ }^{28}$ In a propensity score-matched analysis of the MSBase registry data, we demonstrated that patients switching to fingolimod due to previous on-treatment MS activity experienced less post-switch relapses when compared to those switching to another injectable DMTs. ${ }^{16}$ Moreover, we reported a relatively improved short-term disability outcomes in the fingolimod group.

The efficacy of monotherapy with natalizumab was evaluated in the phase III randomised placebo-controlled AFFIRM trial, with the benefit of natalizumab on relapse activity, disability and MRI activity shown over 24 months. ${ }^{29}$ In addition, natalizumab was associated with a marked increase in the proportion of patients free from all disease activity. ${ }^{30}$ None of

\section{John Wiley \& Sons}

This article is protected by copyright. All rights reserved. 
these trials specifically recruited patients switching therapy after treatment failure; both DMT-treated and treatment-naïve patients were included in these trials. A sub-group analysis of TRANSFORMS showed a $61 \%$ relative reduction of ARR in patients with high pre-trial disease activity on interferon $\beta$ switching to fingolimod versus switching to interferon $\beta$-1a. ${ }^{11}$

The SENTINEL trial evaluated the effect of natalizumab as add-on to interferon $\beta$ in patients experiencing relapses within the year preceding randomisation. ${ }^{10}$ The trial demonstrated superior effect of add-on natalizumab compared to interferon $\beta$ monotherapy in reducing relapses, disability progression events and MRI activity.

While we did not observe any differences in the rate of sustained disability progression between the compared switch strategies, we found a significantly increased probability of sustained disability regression after switch to natalizumab. A possible interpretation is that, while both strategies of DMT switch are very effective in delaying disability progression, natalizumab is superior in promoting recovery from recently accumulated disability in active MS. ${ }^{31}$ This phenomenon is likely responsible for the decrease in overall burden of disability (quantified as the area under EDSS-time curve ${ }^{20,21}$ ) among patients switching to natalizumab but not fingolimod. Our findings are in agreement with the post-hoc analysis of the AFFIRM trial, which showed increase in the 2-year probability of EDSS improvement by $69 \%$ in the natalizumab cohort (30\%) vs. placebo (19\%) at two years, ${ }^{31}$ an effect further confirmed by other retrospective studies. ${ }^{32,33}$ No similar effect has previously been reported for fingolimod.

Our observed relapse rates on fingolimod were higher compared to the phase III trials $(0 \cdot 4 \mathrm{vs} .0 \cdot 11-0 \cdot 21$, respectively $) .{ }^{9,27,28}$ This is likely due to the differences in relapse definition, as the pivotal fingolimod studies only considered relapses confirmed by significant changes on neurological examination. In addition, we have selectively included patients with recent activity on DMT (a known predictor of post-switch activity on fingolimod ${ }^{34}$ ), who had more active disease than the population studied in the fingolimod trials. In contrast, our observed ARR on natalizumab $(0 \cdot 2)$ was similar to the ARR reported in the AFFIRM trial $(0 \cdot 2$, patients with no recent previous DMT) and lower than the ARR reported in the SENTINEL trial (0·34-0.38) despite the high pre-baseline activity. ${ }^{29}$

The main limitation of our study was the follow-up duration, as less than $10 \%$ of the patients were followed for more than 2 years post-switch. We will examine the long-term disability outcomes as the exposure to both DMTs in the MSBase cohort increases. No time-dependent variation (that would suggest differential time-dependent treatment response of the two compared switch strategies) in the relapse and disability outcomes was observed, as indicated by Figure $4 \mathrm{C}$ and the analyses of disability outcomes satisfied the proportionality of hazards assumption. Generalisation of our findings may be limited by the fact that the studied population was largely recruited from tertiary MS centres. To adjust the analysis for 
treatment indication bias, we employed propensity score-matching procedures, which eliminated or reduced known or suspected confounders of treatment allocation. Unlike randomisation, propensity-based matching cannot eliminate unknown confounders. However, we have shown that our analysis was moderately resistant to unknown bias. In addition, our sensitivity analyses confirmed the outcomes of the primary analysis using various inclusion criteria and analysis adjustments. While a proportion of the baseline MRI information was missing, we have shown in a sensitivity analysis that differential availability of this information was unlikely to significantly influence the conclusions drawn. The presumed preferential choice of a therapy that is perceived as more effective for treatment of more severe MS would have confounded the results in favour of fingolimod. Therefore, any potential residual indication bias in our analysis was likely to underestimate rather than overestimate the real difference between the outcomes of the natalizumab and fingolimod switch. Pairwise censoring was applied in order to eliminate attrition bias and to ensure the validity throughout the study of the patient match completed at baseline. Choice of escalation therapy is not only dictated by the DMT efficacy, but is also determined by treatment safety and tolerability. The presence of JC virus antibodies is therefore important information that contributes to the choice of treatment escalation strategy. In this study, we did not evaluate safety and tolerability of the examined therapies, as the availability of this information within the MSBase registry was limited. However, we showed high 2-year treatment persistence on both DMTs.

Both natalizumab and fingolimod significantly reduce relapse activity in patients who switch therapy from interferon $\beta$ or glatiramer acetate due to recent disease activity, and the rates of confirmed progression of disability events post-switch are highly similar. This analysis suggests that switch to natalizumab is more effective than switch to fingolimod in reducing relapses and promoting reduction of disability. Extended post-escalation follow-up is required to compare the effect of these therapeutic strategies on long-term outcomes. 


\section{ACKNOWLEDGEMENTS}

The work was supported by the Multiple Sclerosis Research Australia Postdoctoral Fellowship [11-054], NHMRC Early Career Fellowship [1071124], NHMRC Career Development Award [628856], NHMRC Project Grant [1032484], NHMRC Centre for Research Excellence [Grant ID 1001216] and the MSBase Foundation. The MSBase Foundation is a not-for-profit organization that receives support from Merck Serono, Biogen Idec, Novartis Pharma, Bayer-Schering, Sanofi-Aventis and BioCSL. DH and EH are recipients of the PRVOUK-P26/LF1/4 and NT13237-4/2012 grants. The study was conducted separately and apart from the guidance of the sponsors. TK takes responsibility for the integrity of the data and analyses. The list of MSBase Study Group co-investigators and contributors is given in online Supplementary Table 1.

\section{Authors' roles and contributions}

Tomas Kalincik conceptualised and designed the study, conducted and interpreted the analysis, and drafted, revised and approved the manuscript. Dana Horakova, Timothy Spelman, Vilija Jokubaitis, Maria Trojano, Alessandra Lugaresi, Guillermo Izquierdo, Csilla Rozsa, Pierre Grammond, Raed Alroughani, Pierre Duquette, Marc Girard, Eugenio Pucci, Jeannette Lechner-Scott, Mark Slee, Ricardo Fernandez-Bolanos, Francois Grand'Maison, Raymond Hupperts, Freek Verheul, Suzanne Hodgkinson, Celia Oreja-Guevara, Daniele Spitaleri, Michael Barnett, Murat Terzi, Roberto Bergamaschi, Pamela McCombe, Jose L Sanchez-Menoyo, Magdolna Simo, Tunde Csepany, Gabor Rum, Cavit Boz, Eva Havrdova, and Helmut Butzkueven contributed substantially to data acquisition, interpretation of the analysis, and have revised and approved the manuscript.

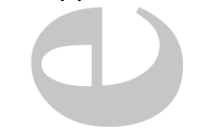

\section{Potential conflicts of interests}

Alessandra Lugaresi is a Bayer Schering, Biogen Idec, Genzyme, Merck Serono Advisory Board Member. She received travel grants and honoraria from Bayer Schering, Biogen Idec, Merck Serono, Novartis, Sanofi Aventis and Teva, research grants from Bayer Schering, Biogen Idec, Merck Serono, Novartis, Sanofi Aventis and Teva, travel and research grants from the Associazione Italiana Sclerosi Multipla.

Cavit Boz has received travel grants from Merck Serono, Biogen Idec, Novartis, Bayer-Schering, Merck-Serono and Teva; has participated in clinical trials by Sanofi Aventis, Roche and Novartis.

\section{John Wiley \& Sons}

This article is protected by copyright. All rights reserved. 
Celia Oreja-Guevara received honoraria as consultant on scientific advisory boards from Biogen-Idec, Bayer-Schering, Merck-Serono, Teva and Novartis; has participated in clinical trials/other research projects by Biogen-Idec, GSK, Teva and Novartis.

Csilla Rozsa has received speaker honoraria from Bayer Schering, Novartis and Biogen Idec, congress and travel expense compensations from Biogen Idec, Teva, Merck Serono and Bayer Schering.

Dana Horakova received speaker honoraria and consulting fees from Biogen Idec, Merck Serono, Teva and Novartis, as well as support for research activities from Biogen Idec.

Daniele LA Spitaleri received honoraria as a consultant on scientific advisory boards by Bayer-Schering, Novartis and SanofiAventis and compensation for travel from Novartis, Biogen Idec, Sanofi Aventis, Teva and Merck-Serono.

Eugenio Pucci served on scientific advisory boards for Genzyme and Biogen-Idec; he has received honoraria and travel grants from Sanofi Aventis, UCB, Lundbeck, Novartis, Bayer Schering, Biogen Idec, Merck Serono, Genzyme and Teva; he has received travel grants from Associazione Marchigiana Sclerosi Multipla e altre malattie neurologiche.

Eva Havrdova received speaker honoraria and consultant fees from Biogen Idec, Merck Serono, Novartis, Genzyme and

Teva, as well as support for research activities from Biogen Idec and Merck Serono.

Francois Grand'Maison received honoraria or research funding from Biogen Idec, Genzyme, Novartis, Teva Neurosciences, Mitsubishi and ONO Pharmaceuticals.

Freek Verheul is an advisory board member for Teva, Biogen, Merck Serono and Novartis.

Gabor Rum received speaker honoraria from Bayer Schering, Novartis and Biogen Idec, congress and travel expense compensations from Biogen Idec and Merck Serono.

Guillermo Izquierdo received speaking honoraria from Biogen-Idec, Novartis, Sanofi, Merck Serono and Teva.

Helmut Butzkueven has served on scientific advisory boards for Biogen Idec, Novartis and Sanofi-Aventis and has received conference travel support from Novartis, Biogen Idec and Sanofi Aventis. He serves on steering committees for trials conducted by Biogen Idec and Novartis, and has received research support from Merck Serono, Novartis and Biogen Idec. Jeannette Lechner-Scott has accepted travel compensation from Novartis, Biogen and Merck Serono. Her institution receives the honoraria for talks and advisory board commitment and also clinic support from Bayer Health Care, Biogen Idec, CSL, Genzyme Sanofi, Merck Serono and Novartis.

Jose L Sanchez-Menoyo has accepted travel compensation from Novartis and Biogen, speaking honoraria from Biogen-Idec, Novartis, Sanofi, Merck Serono, Almirall, Bayer and Teva and has participated in a clinical trial by Biogen-Idec. 
Marc Girard received consulting fees from Teva Canada Innovation, Biogen Idec, Novartis and Genzyme Sanofi; lecture payments from Teva Canada Innovation, Novartis and EMD Serono. Dr Girard has also received a research grant from Canadian Institutes of Health Research.

Maria Trojano received speaking honoraria from Biogen-Idec, Bayer-Schering, Sanofi Aventis, Merck-Serono, Teva and Novartis; has received research grants from Biogen-Idec, Merck-Serono, and Novartis.

Mark Slee has participated in, but not received honoraria for, advisory board activity for Biogen Idec, Merck Serono, Bayer Schering, Sanofi Aventis and Novartis.

Michael Barnett has served on scientific advisory boards for Biogen-Idec, Novartis and Genzyme and has received conference travel support from Biogen-Idec and Novartis. He serves on steering committees for trials conducted by Novartis. His institution has received research support from Biogen-Idec, Merck-Serono and Novartis.

Magdolna Simo received speaker honoraria from Novartis, Biogen Idec, Bayer Schering; congress/travel compensation from Teva, Biogen Idec, Merck Serono, Bayer Schering.

Murat Terzi received travel grants from Merck Serono, Novartis, Bayer-Schering, Merck-Serono and Teva; has participated in clinical trials by Sanofi Aventis, Roche and Novartis.

Pamela McCombe has received honoraria and consulting fees from Novartis, Bayer Schering and Sanofi and travel grants from Novartis, Biogen Idec and Bayer Schering.

Pierre Duquette did not declare any competing interests.

Pierre Grammond is a Novartis, Teva-neuroscience, Biogen Idec and Genzyme advisory board member, consultant for Merck Serono, received payments for lectures by Merck Serono, Teva-Neuroscience and Canadian Multiple sclerosis society, and received grants for travel from Teva-Neuroscience and Novartis.

Raed Alroughani received honororia from Biologix, Bayer, Merck Sorono, Genpharm, GSK and Novartis, and served on advisory board for Biologix, Bayer, Novartis, Genzyme, Genpahrm and Merck Sorono.

Raymond Hupperts received honoraria as consultant on scientific advisory boards from Merck-Serono, Biogen-Idec, Genzyme-Sanofi and Teva, research funding from Merck-Serono and Biogen-Idec, and speaker honoraria from Sanofi-

Genzyme and Novartis.

Ricardo Fernandez-Bolanos received speaking honoraria from Biogen-Idec, Novartis, Merck Serono and Teva. Roberto Bergamaschi received speaker honoraria from Bayer Schering, Biogen Idec, Genzyme, Merck Serono, Novartis, Sanofi-Aventis, Teva; research grants from Bayer Schering, Biogen Idec, Merck Serono, Novartis, Sanofi-Aventis, Teva; congress and travel/accommodation expense compensations by Almirall, Bayer Schering, Biogen Idec, Genzyme, Merck Serono, Novartis, Sanofi-Aventis, Teva. 
Suzanne Hodgkinson did not declare any competing interests.

Timothy Spelman received compensation for travel from Biogen Idec.

Tomas Kalincik received conference travel support and consultancy/speaker honoraria from Novartis, Biogen Idec, Sanofi

Aventis, Genzyme, Teva and Merck Serono.

Tunde Csepany received speaker honoraria/ conference travel support from Bayer Schering, Biogen Idec, Merck Serono,

Novartis and Teva.

Vilija Jokubaitis has received conference travel support from Novartis.
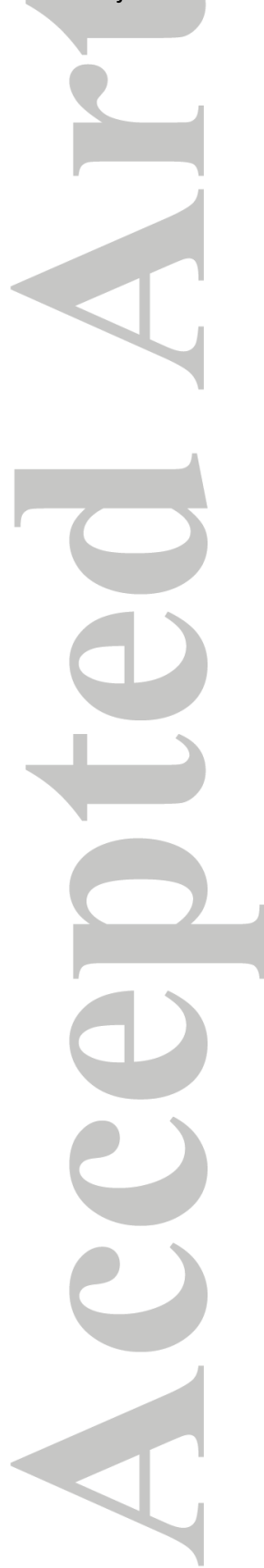


\section{REFERENCES}

1. Goodin DS, Jones J, Li D, et al. Establishing Long-Term Efficacy in Chronic Disease: Use of Recursive Partitioning and Propensity Score Adjustment to Estimate Outcome in MS. PLoS One. 2012;6(11):e22444.

2. The IFNB Multiple Sclerosis Study Group. Interferon beta-1b is effective in relapsing-remitting multiple sclerosis. I. Clinical results of a multicenter, randomized, double-blind, placebo-controlled trial. Neurology. 1993 Apr;43(4):655-61.

3. PRISMS (Prevention of Relapses and Disability by Interferon beta-1a Subcutaneously in Multiple

Sclerosis) Study Group. Randomised double-blind placebo-controlled study of interferon beta-1a in

relapsing/remitting multiple sclerosis. Lancet. 1998 Nov 7;352(9139):1498-504.

4. Jacobs LD, Cookfair DL, Rudick RA, et al. Intramuscular interferon beta-1a for disease progression in relapsing multiple sclerosis. The Multiple Sclerosis Collaborative Research Group (MSCRG). Ann Neurol. 1996 Mar;39(3):285-94.

\section{Johnson KP, Brooks BR, Cohen JA, et al. Copolymer 1 reduces relapse rate and improves disability in} relapsing-remitting multiple sclerosis: results of a phase III multicenter, double-blind placebo-controlled trial.

The Copolymer 1 Multiple Sclerosis Study Group. Neurology. 1995 Jul;45(7):1268-76.

6. Trojano $M$, Pellegrini F, Fuiani A, et al. New natural history of interferon-beta-treated relapsing multiple sclerosis. Ann Neurol. 2007 Apr;61(4):300-6.

$7 . \quad F i l i p p i n i$ G, Del Giovane C, Vacchi L, et al. Immunomodulators and immunosuppressants for multiple sclerosis: a network meta-analysis. Cochrane Database of Systematic Reviews. 2013;6:CD008933-CD.

8. Havrdova E, Galetta S, Stefoski D, Comi G. Freedom from disease activity in multiple sclerosis.

\section{Neurology. 2010 Apr 27;74 Suppl 3:S3-7.}

9. Cohen JA, Barkhof F, Comi G, et al. Oral Fingolimod or Intramuscular Interferon for Relapsing Multiple Sclerosis. N Engl J Med. 2010;362(5):402-15.

10. Rudick RA, Stuart WH, Calabresi PA, et al. Natalizumab plus interferon beta-1a for relapsing multiple sclerosis. N Engl J Med. 2006 Mar 2;354(9):911-23.

\section{John Wiley \& Sons}

This article is protected by copyright. All rights reserved. 
11. Cohen JA, Barkhof F, Comi G, et al. Fingolimod versus intramuscular interferon in patient subgroups from TRANSFORMS. J Neurol. 2013 Aug;260(8):2023-32.

12. Freedman MS. Treatment options for patients with multiple sclerosis who have a suboptimal response to interferon-beta therapy. Eur J Neurol. 2014 Mar;21(3):377-e20.

13. Shirani A, Zhao Y, Karim ME, et al. Association between use of interferon beta and progression of disability in patients with relapsing-remitting multiple sclerosis. JAMA : the journal of the American Medical Association. 2012 Jul 18;308(3):247-56.

14. Kalincik T, Spelman T, Trojano M, et al. Persistence on therapy and propensity matched outcome comparison of two subcutaneous interferon beta 1a dosages for multiple sclerosis. PLoS One. 2013;8(5):e63480.

15. Kalincik $\mathrm{T}$, Jokubaitis V, Izquierdo G, et al. Comparative effectiveness of glatiramer acetate and interferon beta formulations in relapsing-remitting multiple sclerosis. Mult Scler. in press.

16. He A, Spelman T, Jokubaitis VG, et al. Comparison of switch to fingolimod or interferon beta/glatiramer acetate in active multiple sclerosis. JAMA Neurology. in press.

17. Butzkueven $\mathrm{H}$, Chapman J, Cristiano $\mathrm{E}$, et al. MSBase: an international, online registry and platform for collaborative outcomes research in multiple sclerosis. Mult Scler. 2006 Dec;12(6):769-74.

18. Kalincik $T$, Vivek $V$, Jokubaitis $V$, et al. Sex as a determinant of relapse incidence and progressive course of multiple sclerosis. Brain. 2013 Dec;136(Pt 12):3609-17.

19. Schumacher GA, Beebe G, Kibler RF, et al. Problems of Experimental Trials of Therapy in Multiple Sclerosis: Report by the Panel on the Evaluation of Experimental Trials of Therapy in Multiple Sclerosis. Ann N Y Acad Sci. 1965 Mar 31;122:552-68.

20. Liu C, Blumhardt LD. Randomised, double blind, placebo controlled study of interferon beta-1a in relapsing-remitting multiple sclerosis analysed by area under disability/time curves. J Neurol Neurosurg Psychiatry. 1999 Oct;67(4):451-6.

21. Liu C, Po ALW, Blumhardt LD. "Summary measure" statistic for assessing the outcome of treatment trials in relapsing-remitting multiple sclerosis. Journal of Neurology, Neurosurgery \& Psychiatry. 1998 June 1, 1998;64(6):726-9. 
22. R Development Core Team. R: A language and environment for statistical computing. Vienna, Austria: R Foundation for Statistical Computing; 2011.

23. Ho DE, Imai K, King G, Stuart EA. Matching as Nonparametric Preprocessing for Reducing Model Dependence in Parametric Causal Inference. Political Analysis. 2006;15(3):199-236.

24. Carpenter JR, Kenward MG, White IR. Sensitivity analysis after multiple imputation under missing at random: a weighting approach. Statistical methods in medical research. 2007 Jun;16(3):259-75.

25. Heraud-Bousquet V, Larsen C, Carpenter J, Desenclos JC, Le Strat Y. Practical considerations for sensitivity analysis after multiple imputation applied to epidemiological studies with incomplete data. BMC medical research methodology. 2012;12:73.

26. Rosenbaum PR. Observational studies. 2nd ed. New York, NY: Springer-Verlag; 2002.

27. Kappos L, Radue E-W, O'Connor P, et al. A Placebo-Controlled Trial of Oral Fingolimod in Relapsing Multiple Sclerosis. N Engl J Med. 2010;362(5):387-401.

28. Khatri B, Barkhof F, Comi G, et al. Comparison of fingolimod with interferon beta-1a in relapsingremitting multiple sclerosis: a randomised extension of the TRANSFORMS study. Lancet Neurol. 2011

\section{Jun;10(6):520-9.}

29. Polman $\mathrm{CH}, \mathrm{O}$ 'Connor PW, Havrdova E, et al. A randomized, placebo-controlled trial of natalizumab for relapsing multiple sclerosis. N Engl J Med. 2006 Mar 2;354(9):899-910.

30. Havrdova E, Galetta S, Hutchinson M, et al. Effect of natalizumab on clinical and radiological disease activity in multiple sclerosis: a retrospective analysis of the Natalizumab Safety and Efficacy in RelapsingRemitting Multiple Sclerosis (AFFIRM) study. Lancet Neurol. 2009 Mar;8(3):254-60.

31. Phillips JT, Giovannoni G, Lublin FD, et al. Sustained improvement in Expanded Disability Status Scale as a new efficacy measure of neurological change in multiple sclerosis: treatment effects with natalizumab in patients with relapsing multiple sclerosis. Mult Scler. 2011 Aug;17(8):970-9.

32. Putzki N, Yaldizli O, Maurer M, et al. Efficacy of natalizumab in second line therapy of relapsingremitting multiple sclerosis: results from a multi-center study in German speaking countries. Eur J Neurol. 2010 Jan;17(1):31-7. 
33. Belachew S, Phan Ba R, Bartholome E, et al. Natalizumab induces a rapid improvement of disability status and ambulation after failure of previous therapy in relapsing-remitting multiple sclerosis. Eur J Neurol. $2011 ; 18(2): 240-5$

34. Jokubaitis VG, Li V, Kalincik T, et al. Fingolimod after natalizumab and the risk of short-term relapse. Neurology. 2014 Apr 8;82(14):1204-11.
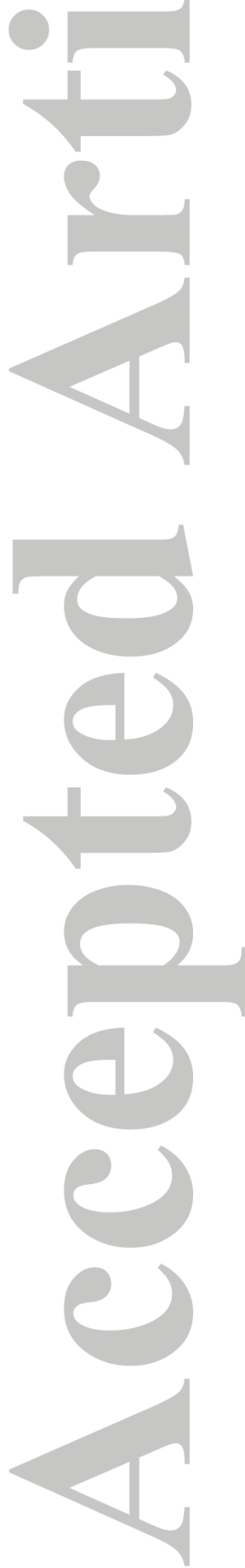


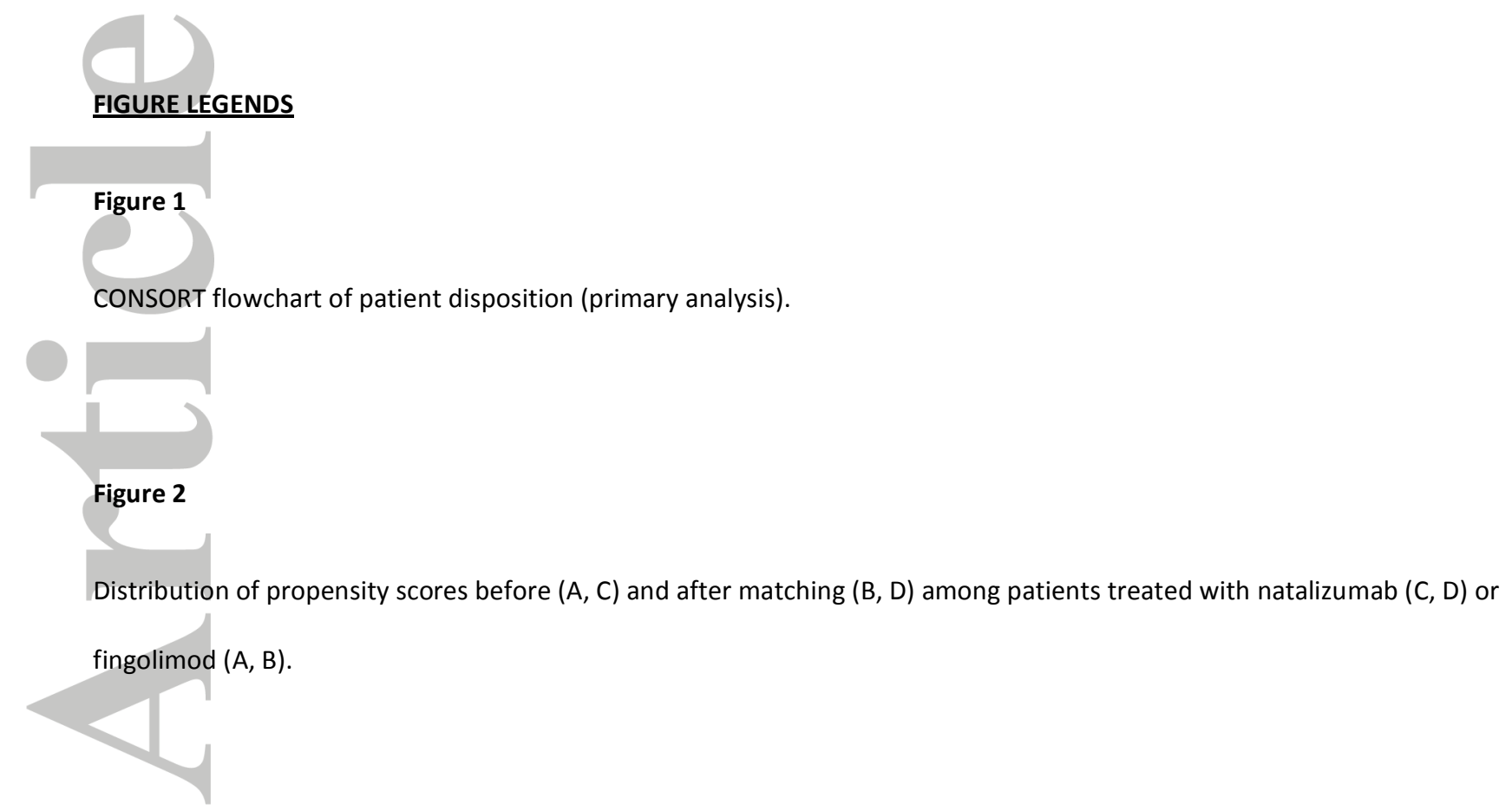

Figure 3

Persistence on natalizumab and fingolimod among the matched patients. Results of paired matched analysis without pairwise censoring are shown. Dashed curves indicate $95 \%$ confidence intervals.
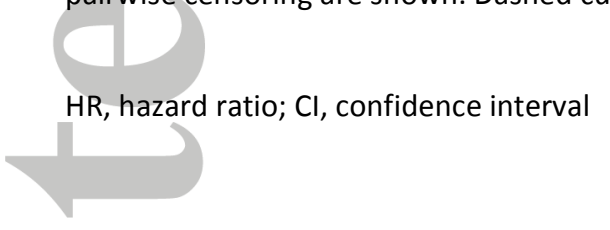

Figure 4

Proportion of pati

Proportion of patients free from clinical relapses (A), overall annualised relapse rate $(B)$ and 6-monthly relapse rate (C) among patients treated with natalizumab or fingolimod. Results of paired matched analyses with pairwise censoring are shown. Dashed curves and error bars indicate $95 \%$ confidence intervals.

$\mathrm{HR}$, hazard ratio; $\mathrm{Cl}$, confidence interval

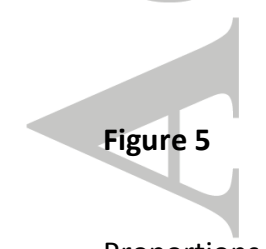

Proportions of patients free from disability progression (A) and those with disability regression (B) confirmed at 6 months. Annualised area under disability-time curve (C) showed decrease after escalation to natalizumab but not fingolimod.

\section{John Wiley \& Sons}

This article is protected by copyright. All rights reserved. 
Results of paired matched analyses with pairwise censoring are shown. Dashed curves and error bars indicate $95 \%$ confidence intervals.

$\mathrm{HR}$, hazard ratio; $\mathrm{Cl}$, confidence interval
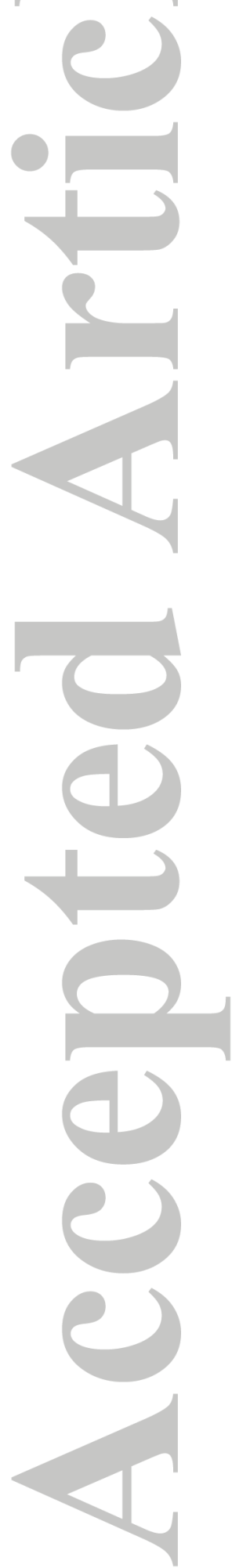


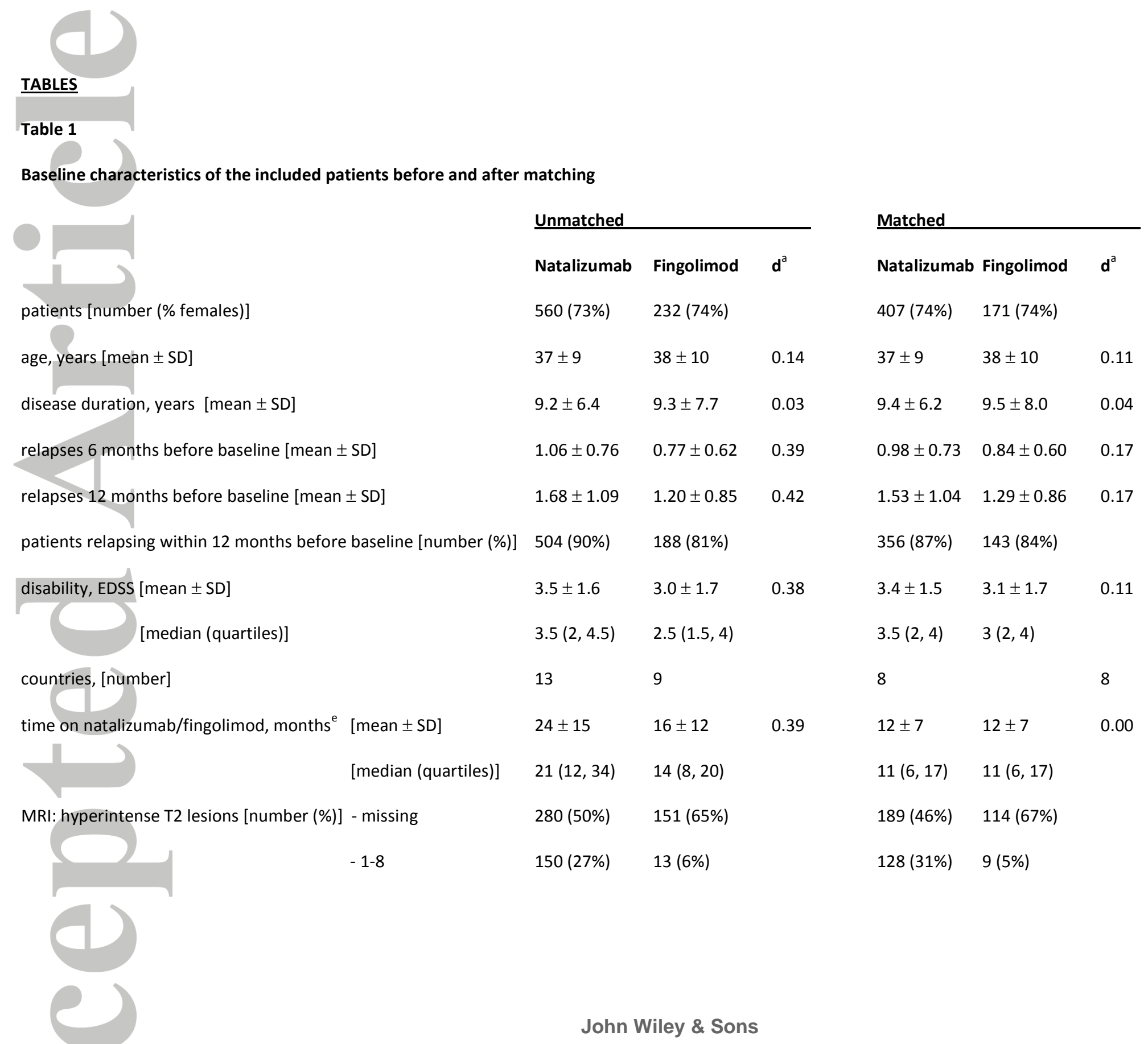




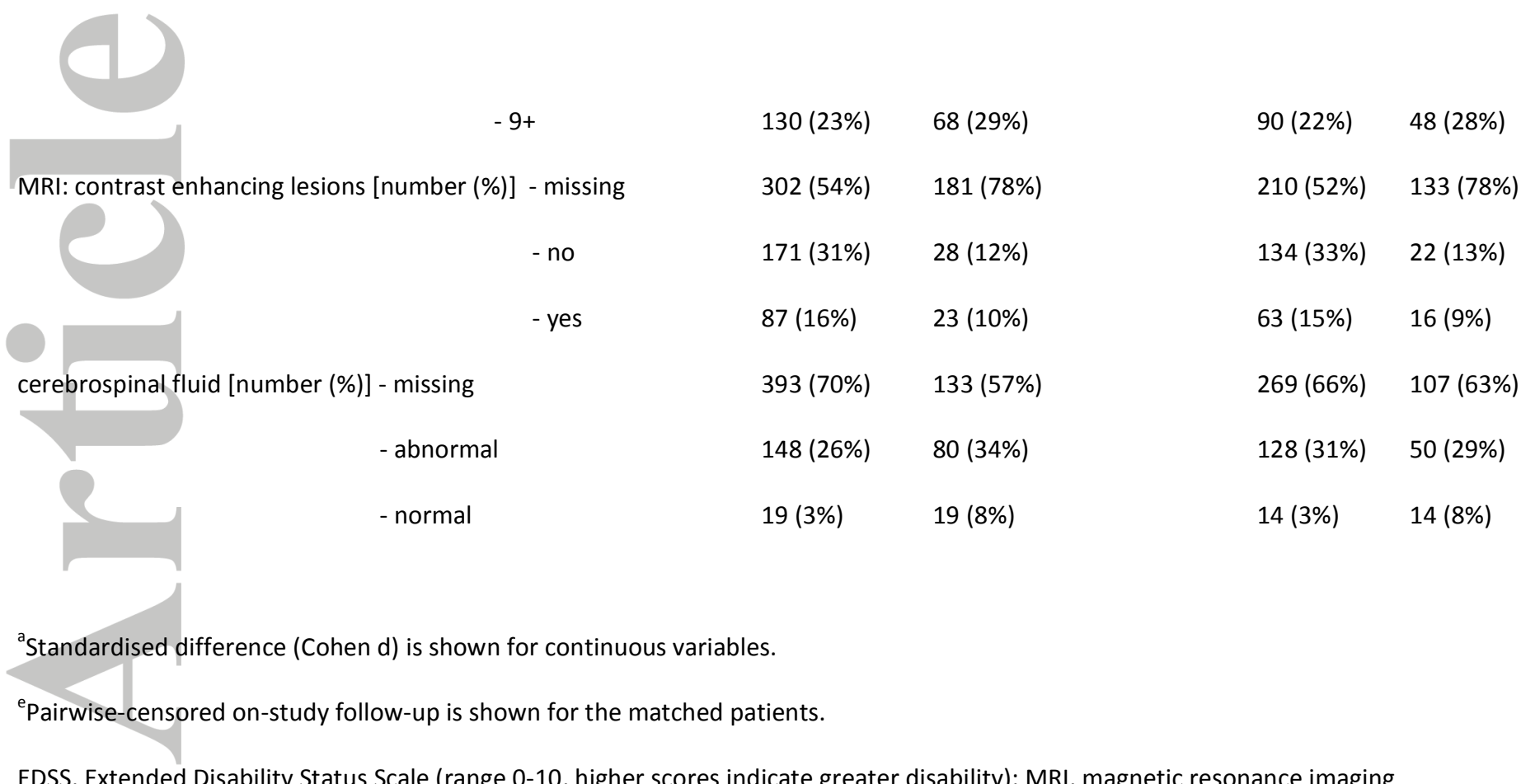

EDSS, Extended Disability Status Scale (range 0-10, higher scores indicate greater disability); MRI, magnetic resonance imaging

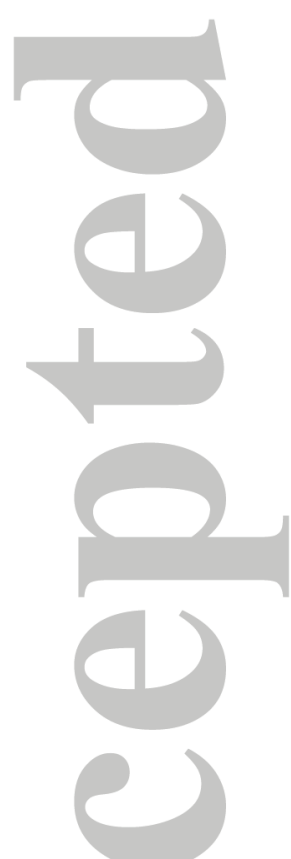




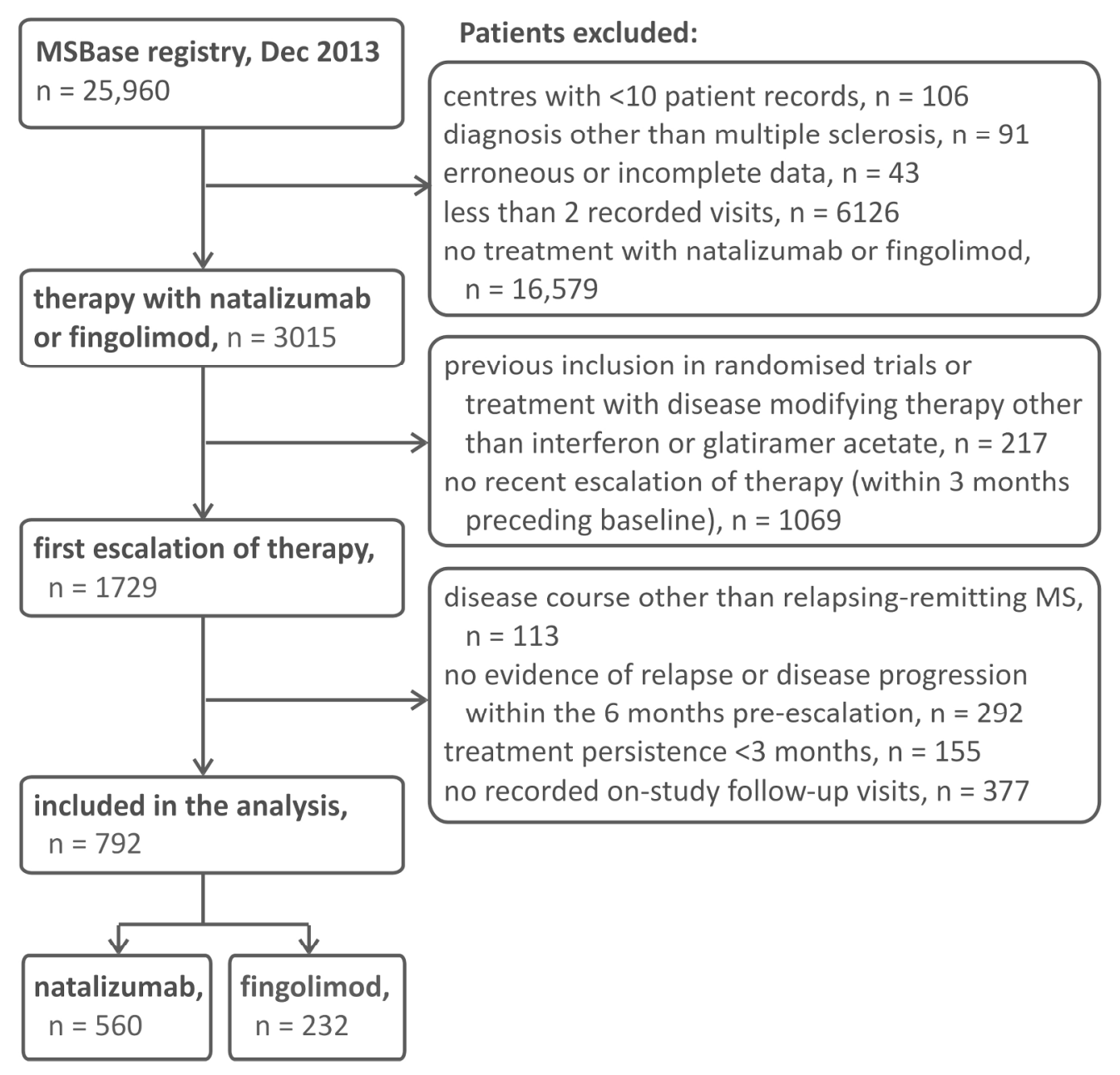

Figure 1: CONSORT flowchart of patient disposition 
A

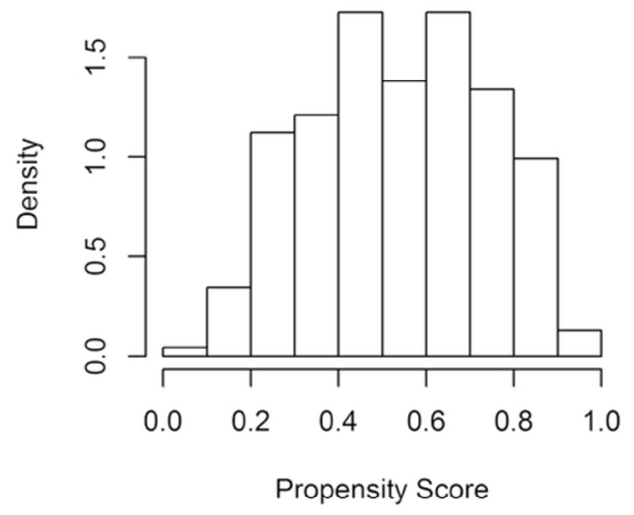

C

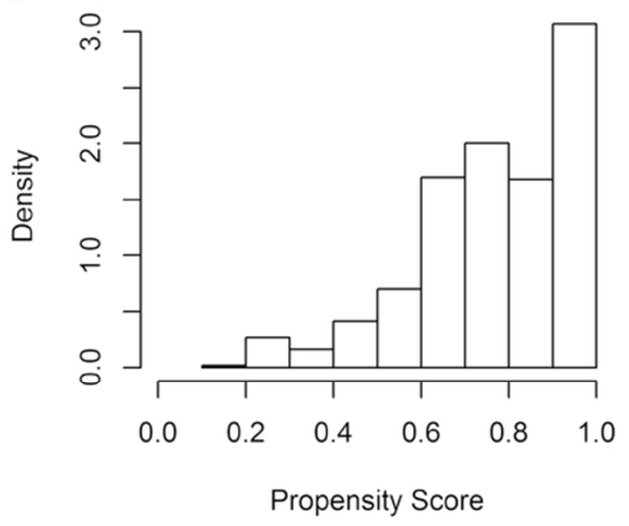

B

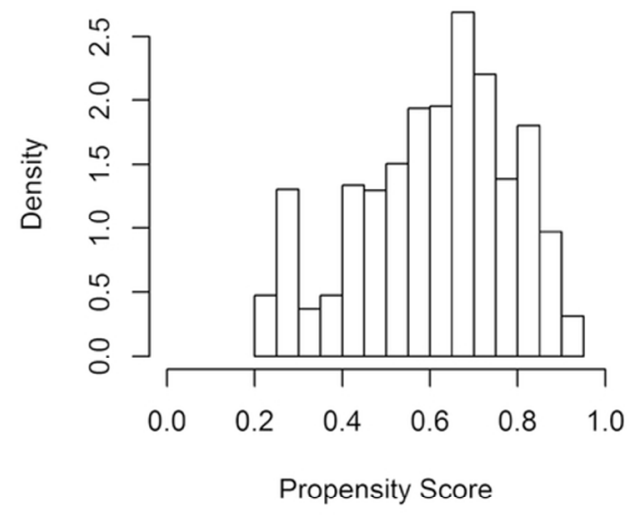

D

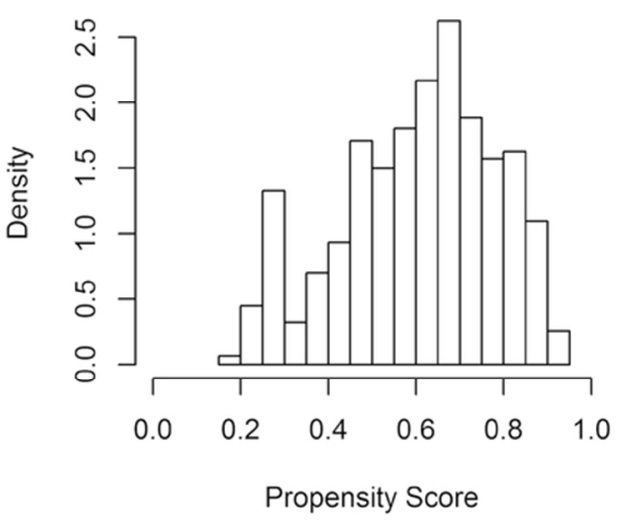

Figure 2: Distribution of propensity scores before and after matching $76 \times 73 \mathrm{~mm}(300 \times 300 \mathrm{DPI})$ 


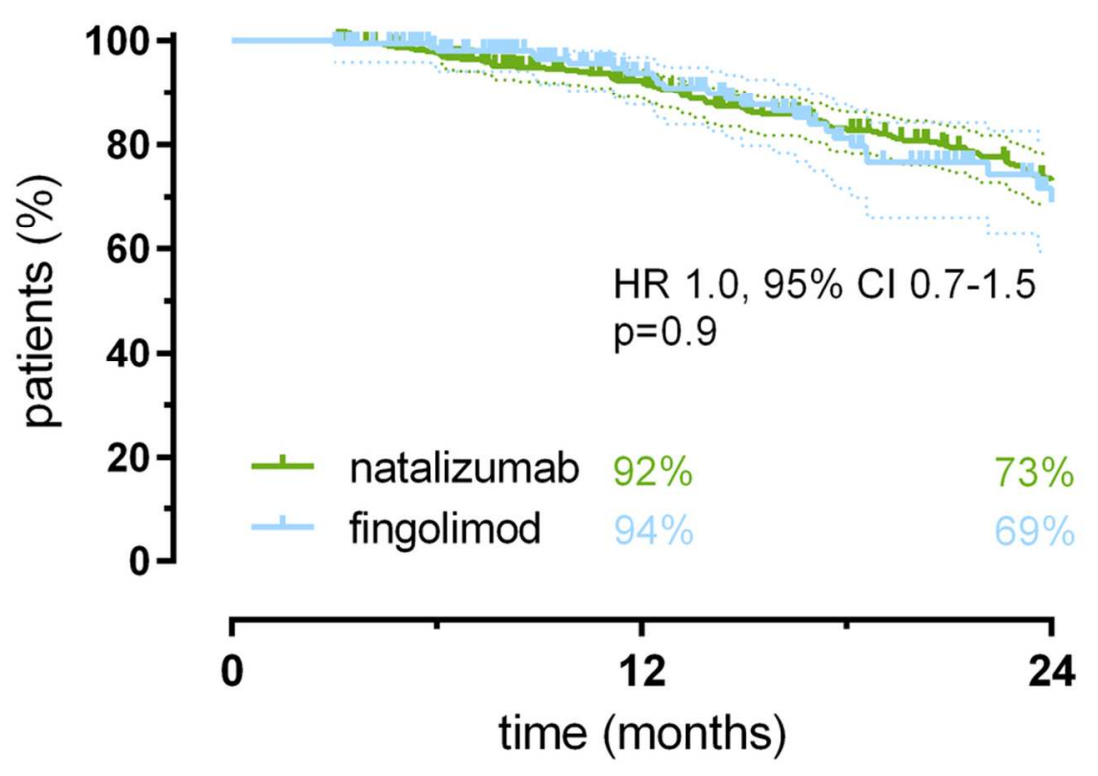

\section{Patients not censored}

$\begin{array}{lrrrrr}\text { natalizumab } & 407 & 384 & 327 & 262 & 210 \\ \text { fingolimod } & 171 & 145 & 99 & 56 & 26\end{array}$

Figure 3: Persistence on natalizumab and fingolimod $92 \times 76 \mathrm{~mm}(300 \times 300 \mathrm{DPI})$ 
A

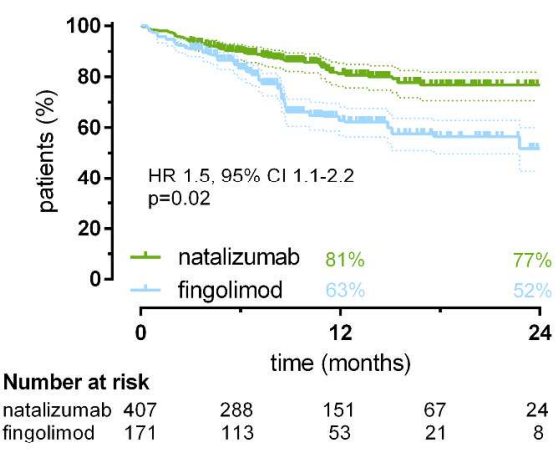

B

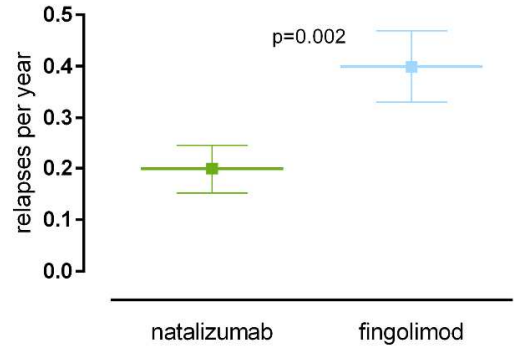

C

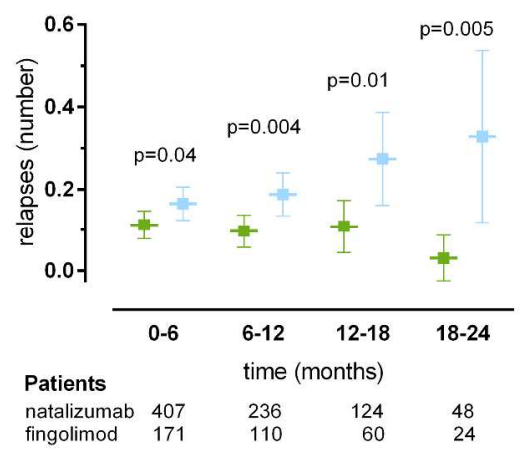

Proportion of patients free from clinical relapses $250 \times 586 \mathrm{~mm}(300 \times 300$ DPI $)$ 


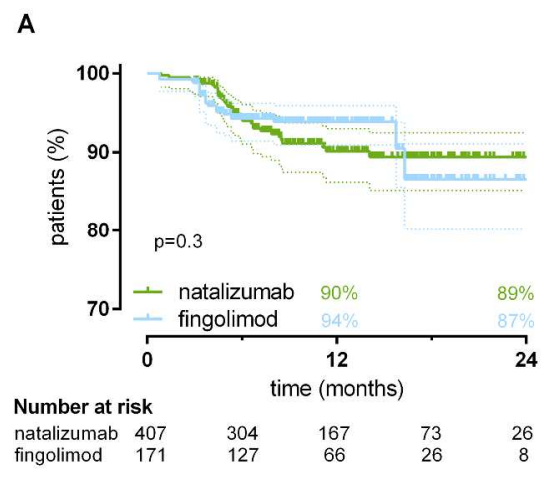

B

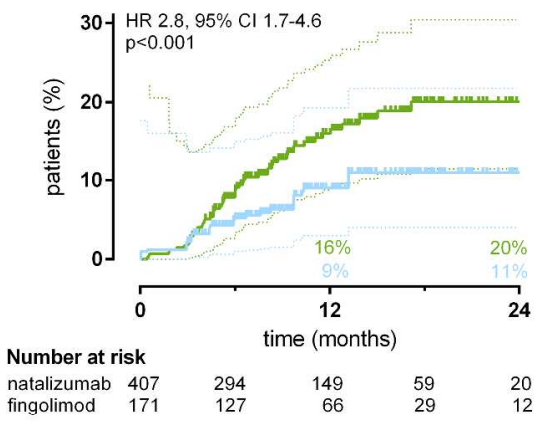

C

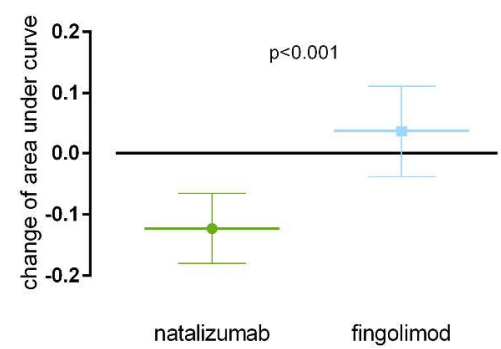

Proportions of patients free from disability progression $263 \times 644 \mathrm{~mm}(300 \times 300$ DPI $)$

\section{John Wiley \& Sons}

This article is protected by copyright. All rights reserved. 


\section{Supplementary Table 1 MSBase study group co-investigators and contributors}

From Department of Basic Medical Sciences, Neuroscience and Sense Organs, University of Bari, Italy, Dr Damiano Paolicelli, Dr Pietro laffaldano, Dr Vita Direnzo and Dr Mariangela D'Onghia; from Aarhus University Hospital, Aarhus C, Denmark, Dr Thor Petersen; from the MS-Centrum Nijmegen, Nijmegen, The Netherlands Dr Cees Zwanikken; from Hospital S. Joao, Porto, Portugal, Maria Edite Rio; from Veszprem Megyei Csolnoky Ferenc Korhaz, Veszprem, Hungary, Dr Imre Piroska; from Jewish General Hospital, Montreal, Canada, Dr Fraser Moore; from Josa Andras Hospital, Nyiregyhaza, Dr Tunde Erdelyi; from Semmelweis University, Budapest, Hungary, Dr Anna Iljicsov; from Peterfy Sandor Hospital, Budapest, Hungary, Dr Kristina Kovacs; from BAZ County Hospital, Miskolc, Hungary, Dr Attila Sas; from The Alfred Hospital and Monash University, Melbourne, Australia, Dr Olga Skibina; from Cliniques Universitaires Saint-Luc, Brussels, Belgium, Dr Vincent Van Pesch; from Ospedali Riuniti di Salerno, Salerno, Italy, Dr Gerardo luliano; from Jeroen Bosch Ziekenhuis, Den Bosch, The Netherlands, Dr Erik van Munster; from FLENI, Buenos Aires, Argentina, Dr Marcela Fiol, Dr Jorge Correale and Dr Celica Ysrraelit; from Department NEUROFARBA, Section of Neurosciences, University of Florence, Florence, Italy, Dr Maria Pia Amato; from Francicus Ziekenhuis, Roosendaal, The Netherlands, Ms Leontien den Braber-Moerland; from New York University Langone Medical Center, New York, USA, Dr Joseph Herbert and Dr Iliya Kister; from Hopital Tenon, Paris, France, Dr Etienne Roullet; from Jahn Ferenc Teaching Hospital, Budapest, Hungary, Dr Krisztian Kasa; from Central Clinical Emergency Military Hospital, Bucharest, Romania, Dr Carmen-Adella Sirbu; from the Geelong Hospital, Geelong, Australia, Dr Cameron Shaw; from HIGA Gral. San Martin, La Plata, Argentina, Dr Santiago Vetere; from the Westmead Hospital, Sydney, Australia, Dr Steve Vucic; from the Clinic of Neurology Clinical Center, Skopje, Macedonia, Dr Tatjana Petkovska-Boskova; from the Bombay Hospital Institute of Medical Sciences, Mumbai, India, Dr Bhim Singhal; from the Instituto de Neurociencias, Cordoba, Argentina, Dr Elizabeth Alejandra Bacile; from the Hospital Ecoville, Brazil, Dr Walter Oleschko Arruda; from the Centre hospitalier del'Universite de Montreal, Hopital Notre-Dame, Canada, Ms Elaine Roger and Mr Pierre Despault; from the Royal Melbourne Hospital, Australia, Dr Mark Marriott, Dr Anneke Van der Walt, Dr John King, Dr Trevor Kilpatrick, Dr Jill Byron, Ms Lisa Morgan and Ms Eloise Hinson; from Box Hill Hospital, Monash University, Australia, Ms Jodi Haartsen; from Department of Neuroscience and Imaging, University 'G. d'Annunzio', Italy, Dr Giovanna De Luca, Dr Valeria Di Tommaso, Dr Daniela Travaglini, Dr Erika Pietrolongo, Dr Maria di loia, Dr Deborah Farina and Dr Luca Mancinelli; from Hospital Italiano, Argentina, Dr Edgardo Cristiano, Dr Juan Ignacio Rojas and Dr Liliana Patrucco; from Ospedale di Macerata, Italy, Dr Elisabetta Cartechini and Dr Giorgio Giuliani; from John Hunter Hospital, Australia, Dr David Williams and Dr Lisa Dark; from Buenos Aires, Argentina, Dr Aldo Savino; from Sheba Medical Center, Tel Hashomer, Israel, Dr Joab Chapman; from Assaf Harofeh Medical Center, Beer-Yaakov, Israel, Dr Shlomo Flechter; from Centro Internacional de Restauracion Neurologica, Havana, Cuba. Dr Jose Antonio Cabrera-Gomez; from INEBA, Buenos Aires, Argentina, Dr Maria Laura Saladino; from Hospital Fernandez, Buenos Aires, Argentina, Dr Norma Deri; from Craigavon Area Hospital, Portadown, UK, Dr Orla Gray; from St Vincent's Hospital, Melbourne, Australia; Dr Mark Paine; from Mater Dei Hospital, Malta; Dr Norbert Vella; and from Rodanotech, Geneva, Switzerland; Mr Samir Mechati, Mr Matthieu Corageoud, and Mr Alexandre Bulla.

No compensation has been received for the persons who have made substantial contributions to the work but do not qualify as authors.

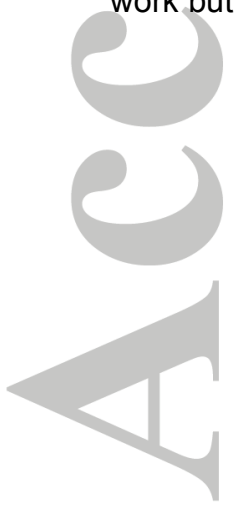

Page 1 of 7 


\section{Supplementary Table 2}

\section{Number of eligible patients per MS Centre}

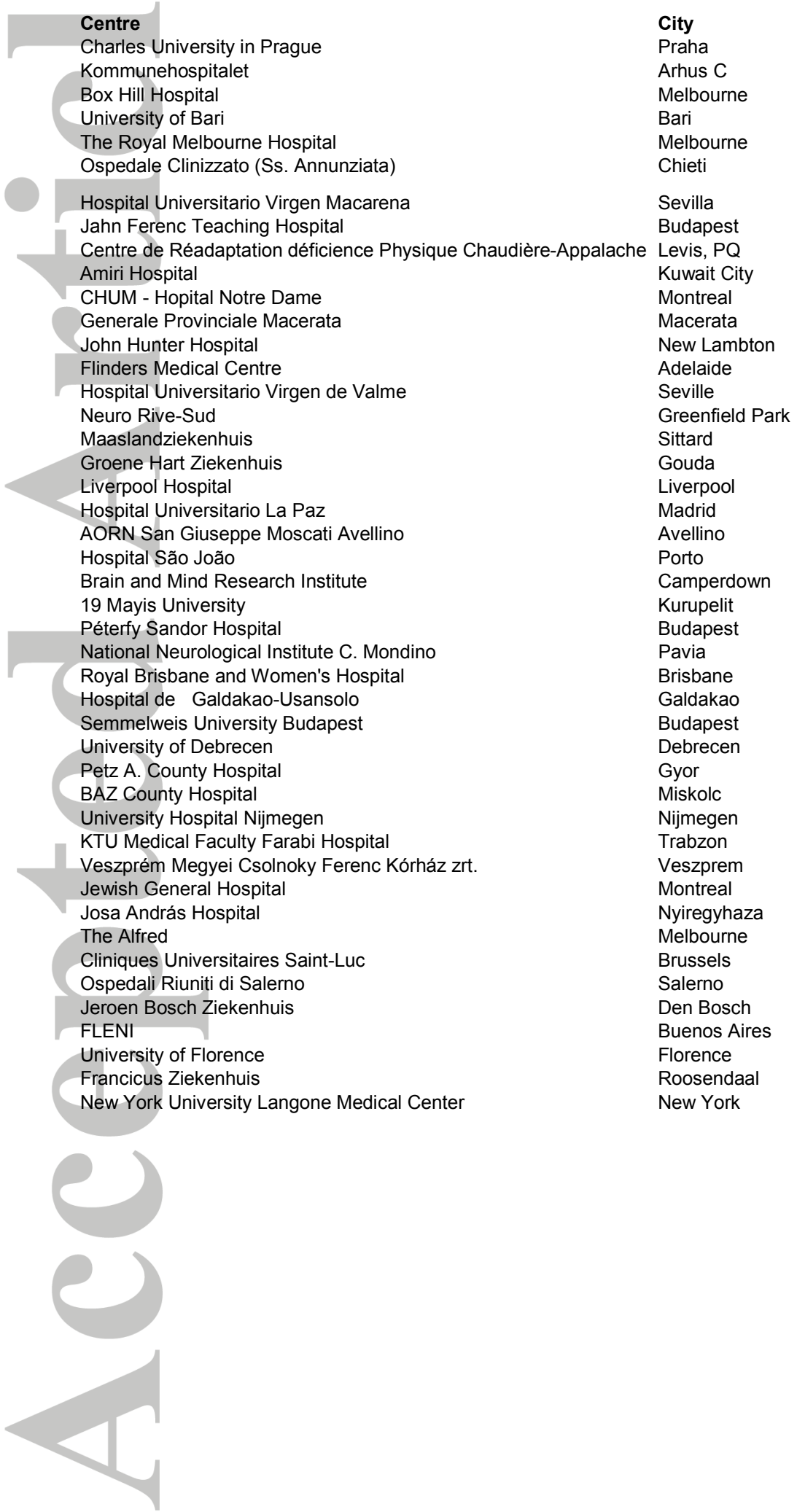

\begin{tabular}{|c|c|}
\hline Country & Patients \\
\hline Czech Republic & 77 \\
\hline Denmark & 54 \\
\hline Australia & 49 \\
\hline Italy & 49 \\
\hline Australia & 48 \\
\hline Italy & 45 \\
\hline Spain & 44 \\
\hline Hungary & 41 \\
\hline Canada & 38 \\
\hline Kuwait & 32 \\
\hline Canada & 31 \\
\hline Italy & 29 \\
\hline Australia & 27 \\
\hline Australia & 24 \\
\hline Spain & 20 \\
\hline Canada & 18 \\
\hline Netherlands & 18 \\
\hline Netherlands & 14 \\
\hline Australia & 13 \\
\hline Spain & 12 \\
\hline Italy & 11 \\
\hline Portugal & 9 \\
\hline Australia & 8 \\
\hline Turkey & 7 \\
\hline Hungary & 6 \\
\hline Italy & 6 \\
\hline Australia & 5 \\
\hline Spain & 5 \\
\hline Hungary & 5 \\
\hline Hungary & 5 \\
\hline Hungary & 5 \\
\hline Hungary & 5 \\
\hline Netherlands & 5 \\
\hline Turkey & 5 \\
\hline Hungary & 4 \\
\hline Canada & 3 \\
\hline Hungary & 3 \\
\hline Australia & 2 \\
\hline Belgium & 2 \\
\hline Italy & 2 \\
\hline Netherlands & 2 \\
\hline Argentina & 1 \\
\hline Italy & 1 \\
\hline Netherlands & 1 \\
\hline United States & 1 \\
\hline
\end{tabular}




\section{Supplementary Table 3}

\section{Study cohort characteristics: pre-study disease activity and therapy}

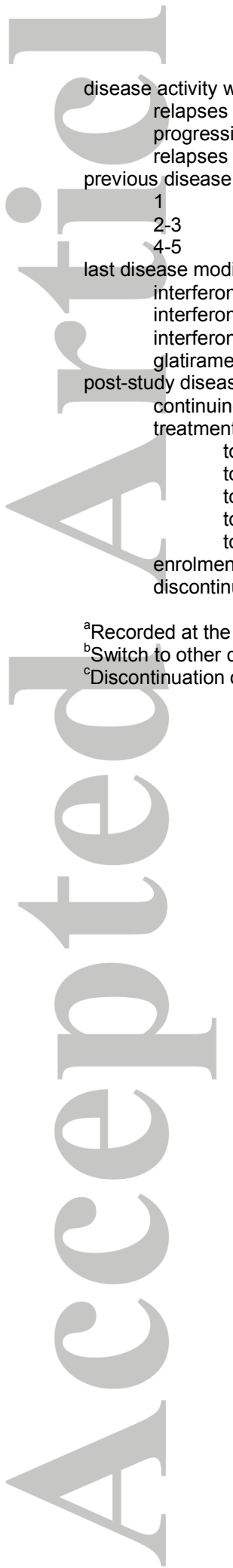

\section{Unmatched \\ Natalizumab \\ Fingolimod}

$$
\text { er }(\%)
$$

$248(44 \%)$

$100(18 \%)$

$212(38 \%)$

$88(38 \%)$
$70(30 \%)$

$74(32 \%)$

$323(58 \%)$

$226(40 \%)$

$11(2 \%)$

$91(16 \%)$

$205(37 \%)$

$115(21 \%)$

$149(27 \%)$

$142(61 \%)$

$85(37 \%)$

$5(2 \%)$

$46(20 \%)$

$82(35 \%)$

$49(21 \%)$

$55(24 \%)$

$359(64 \%)$

$195(84 \%)$

$13(2 \%)$

$27(5 \%)$

0

to glatiramer acetate

to dimethyl fumarate

to fingolimod

to natalizumab

rolment in randomised trial

scontinuation of treatment ${ }^{d}$
$46(8 \%)$

$1(0.2 \%)$

$1(0.2 \%)$

$113(20 \%)$

\section{0}

$1(0.4 \%)$

$8(3 \%)$

0

$27(12 \%)$
$1(0.4 \%)$
Matched

Natalizumab Fingolimod

$171(42 \%) \quad 73(43 \%)$

$88(22 \%) \quad 42(25 \%)$

$148(36 \%) \quad 56(33 \%)$

$239(59 \%) \quad 102(60 \%)$

$159(39 \%) \quad 66(38 \%)$

$9(2 \%) \quad 3(2 \%)$

$62(15 \%) \quad 26(15 \%)$

$161(40 \%) \quad 68(40 \%)$

$85(21 \%) \quad 34(20 \%)$

$99(24 \%) \quad 43(25 \%)$

$230(57 \%) \quad 141(82 \%)$

$11(3 \%) \quad 0$

$23(6 \%) \quad 1(0.6 \%)$

$0 \quad 1(0.6 \%)$

$46(11 \%) \quad 0$

$1(0.2 \%) \quad 8(5 \%)$

$1(0.2 \%) \quad 8(0.2 \%)$

$94(23 \%) \quad 20(12 \%)$

ist the last study entry, prior to pairwise censoring.

Switch to other disease modifying therapy within three months of discontinuing on-study therapy (natalizumab or fingolimod). ${ }^{\mathrm{C}}$ Discontinuation of disease modifying therapy for at least three months. 


\section{Supplementary Table 4}

Determinants of allocation to natalizumab or fingolimod

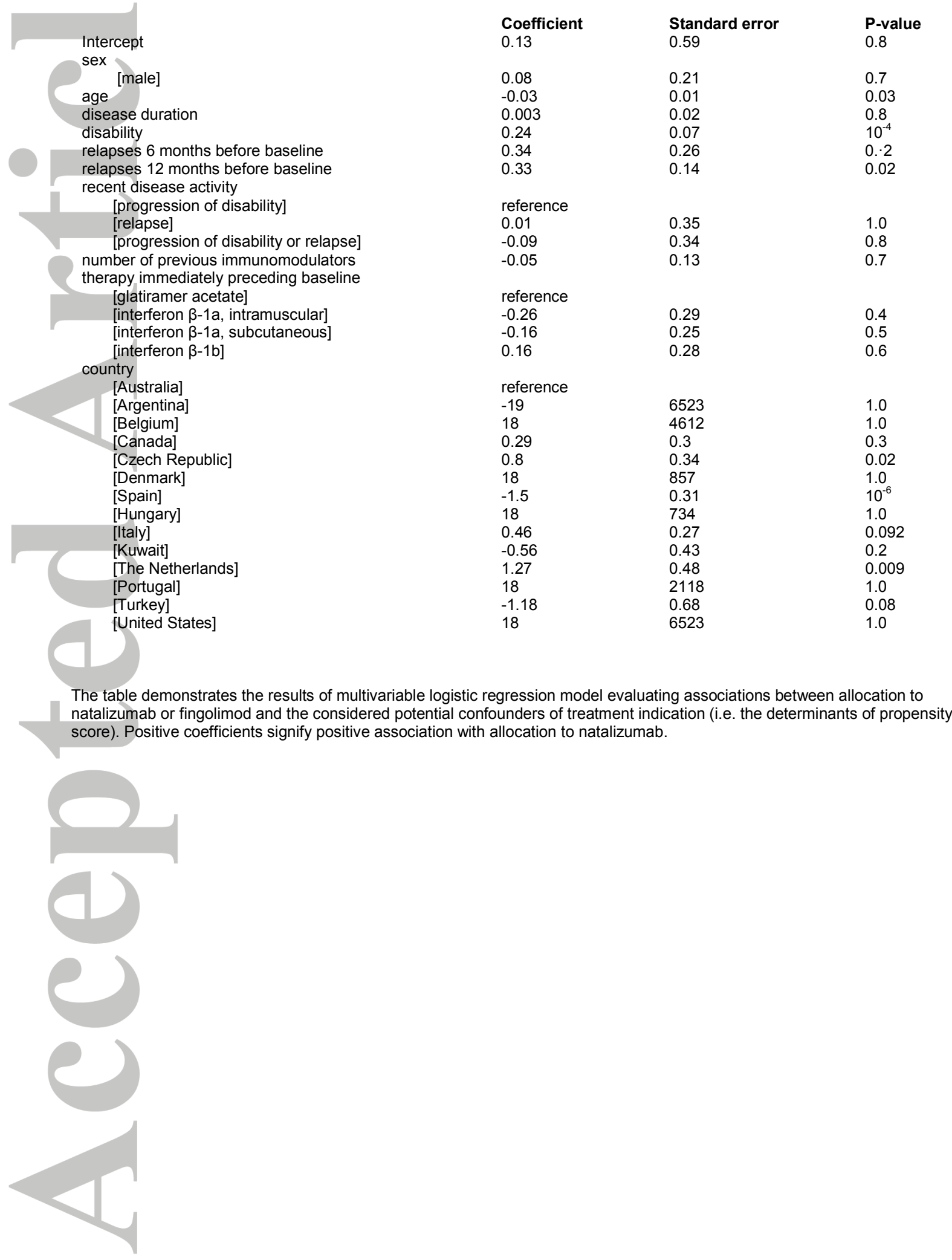




\section{Supplementary Table 5 Sensitivity analyses}

1. Analysis with imputation under Missing Not At Random mechanism

patients

Natalizumab

P-value

unmatched

matched

560

407

treatment discontinuation, hazard ratio $(95 \% \mathrm{Cl})$

$1.08(0.62-1.38)$

232

relapse outcomes

$1.51(1.08-2.10)$

$0.58(0.51-0.81)$

cumulative hazard of relapses, hazard ratio $(95 \% \mathrm{CI})$

annualised relapse rate, mean $\pm S D$

$0.20 \pm 0.46$

$-0.12 \pm 0.71$

area under EDSS-time curve, mean \pm SD

$1.39(0.59-1.56)$

proportion with EDSS progression, hazard ratio $(95 \% \mathrm{Cl})$

$2.92(1.80-4.74)$

171

$\mathrm{n} / \mathrm{s}$

$0.36 \pm 0.67-0.001$

$0.04 \pm 0.58 \quad 10^{-5}$

$\mathrm{n} / \mathrm{s}$

2. No imputation of the missing MRI data ("missing" value allowed)

patients

Natalizumab

Fingolimod

P-value

unmatched

560

407

matched

$1.08(0.62-1.38)$

232

171

relapse outcomes

proportion free from clinical relapses, hazard ratio $(95 \% \mathrm{Cl})$

cumulative hazard of relapses, hazard ratio $(95 \% \mathrm{Cl})$

annualised relapse rate, mean $\pm \mathrm{SD}$

$1.47(1.04-2.07)$

$0.53(0.37-0.75)$

$0.20 \pm 0.46$

$-0.12 \pm 0.71$

area under EDSS-time curve, mean \pm SD

$1.42(0.80-2.53)$

proportion with EDSS progression, hazard ratio $(95 \% \mathrm{CI})$

$2.09(1.29-3.38)$

$\mathrm{n} / \mathrm{s}$

0.03

0.0004

$0.36 \pm 0.67 \quad 0.0002$

$0.04 \pm 0.58 \quad 0.002$

$\mathrm{n} / \mathrm{s}$

0.003

3. Patients with a documented relapse within the 6 months preceding treatment switch

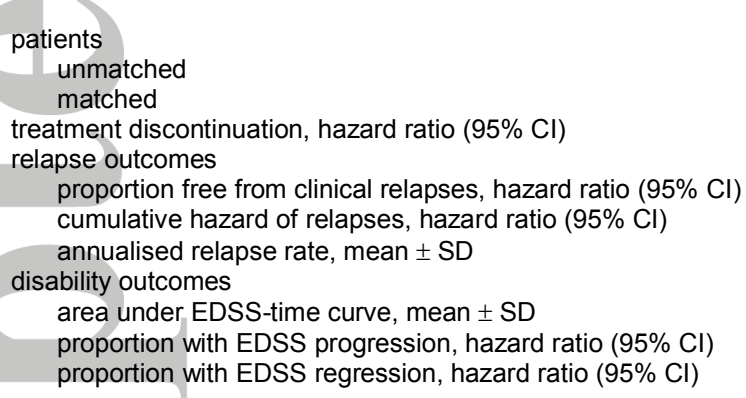

311

$1.32(0 \cdot 92-1 \cdot 90)$

131

$1.48(1.03-2.12)$

$0.50(0.34-0.75)$

$0.18 \pm 0.47$

$0.31 \pm 0.61$

0.03

0.0009

$-0.13 \pm 0.64$

$0.88(0.50-1.56)$

$-0.01 \pm 0.57$

$10^{-5}$

$2.57(1.52-4.36)$

0.02

$\mathrm{n} / \mathrm{s}$

0.0004

\section{Patients irrespective of pre-baseline recent disease activity}

patients

unmatched

matched

treatment discontinuation, hazard ratio $(95 \% \mathrm{Cl})$

relapse outcomes

proportion free from clinical relapses, hazard ratio $(95 \% \mathrm{Cl})$

cumulative hazard of relapses, hazard ratio $(95 \% \mathrm{Cl})$

annualised relapse rate, mean $\pm S D$

disability outcomes

area under EDSS-time curve, mean \pm SD

proportion with EDSS progression, hazard ratio $(95 \% \mathrm{Cl})$

proportion with EDSS regression, hazard ratio $(95 \% \mathrm{Cl})$

Natalizumab

697

524

$0.87(0.57-1.32)$

$1.46(1.09-1.96)$

$0.58(0.42-0.80)$

$0.19 \pm 0.48$

$-0.09 \pm 0.55$

$0.98(0.60-1.61)$

$1.66(1.09-2.52)$
Fingolimod

P-value

387

237

$\mathrm{n} / \mathrm{s}$

0.01

0.0008

$0.36 \pm 0.70$

0.0001

$0.02 \pm 0.60$

0.0004

$\mathrm{n} / \mathrm{s}$

0.02

5. Patients with baseline EDSS recorded between -50 to +7 days of treatment initiation patients

Natalizumab

Fingolimod

P-value

unmatched

348

217

matched

$0.90(0 \cdot 55-1 \cdot 46)$

131

91

treatment discontinuation, hazard ratio $(95 \% \mathrm{Cl})$

relapse outcomes 


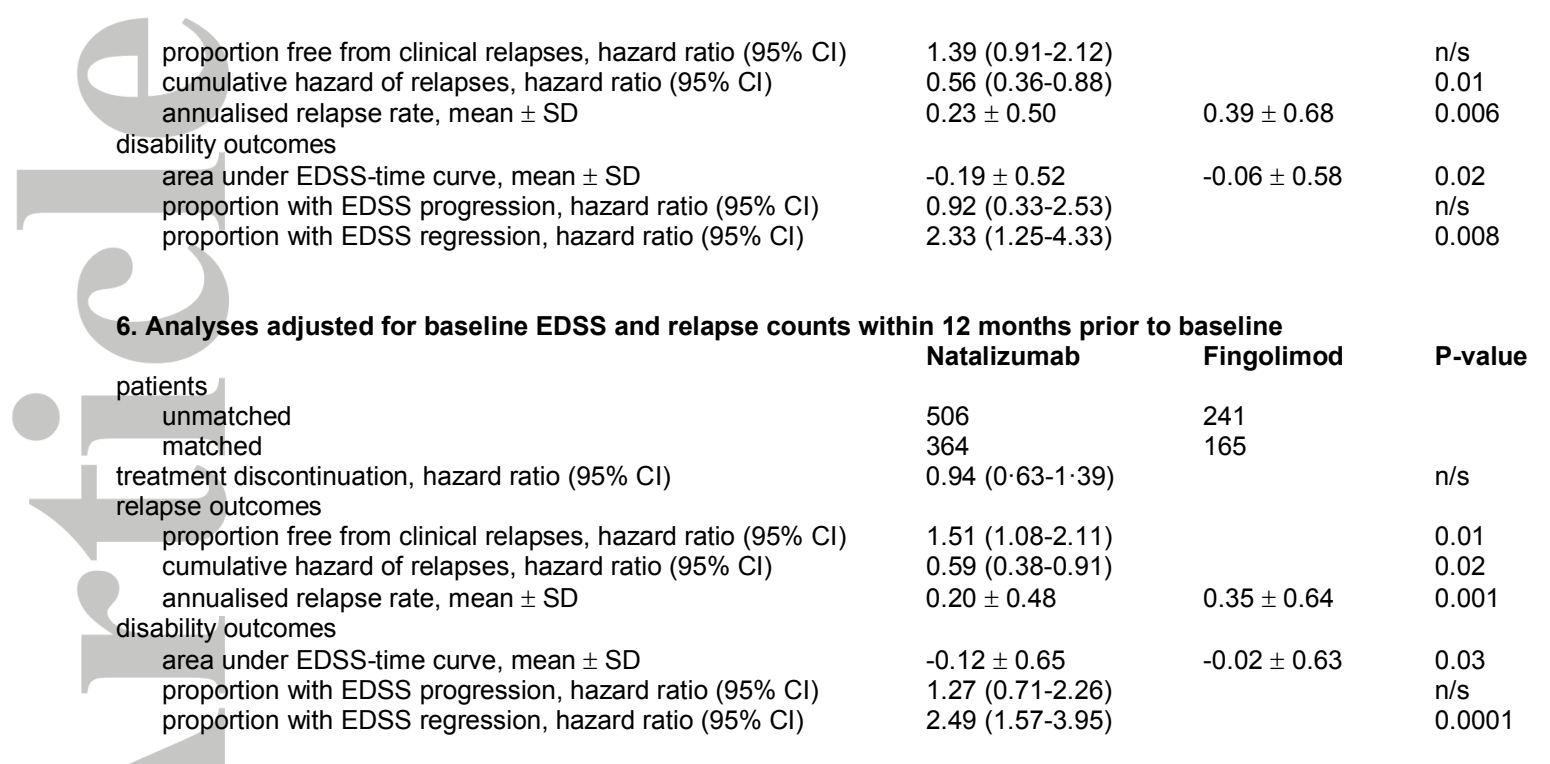

$\mathrm{Cl}$, confidence interval; EDSS, Expanded Disability Status Scale; MRI, magnetic resonance imaging; SD, standard deviation 


\section{Supplementary Table 6}

Associations between the availability of baseline MRI variables and other variables

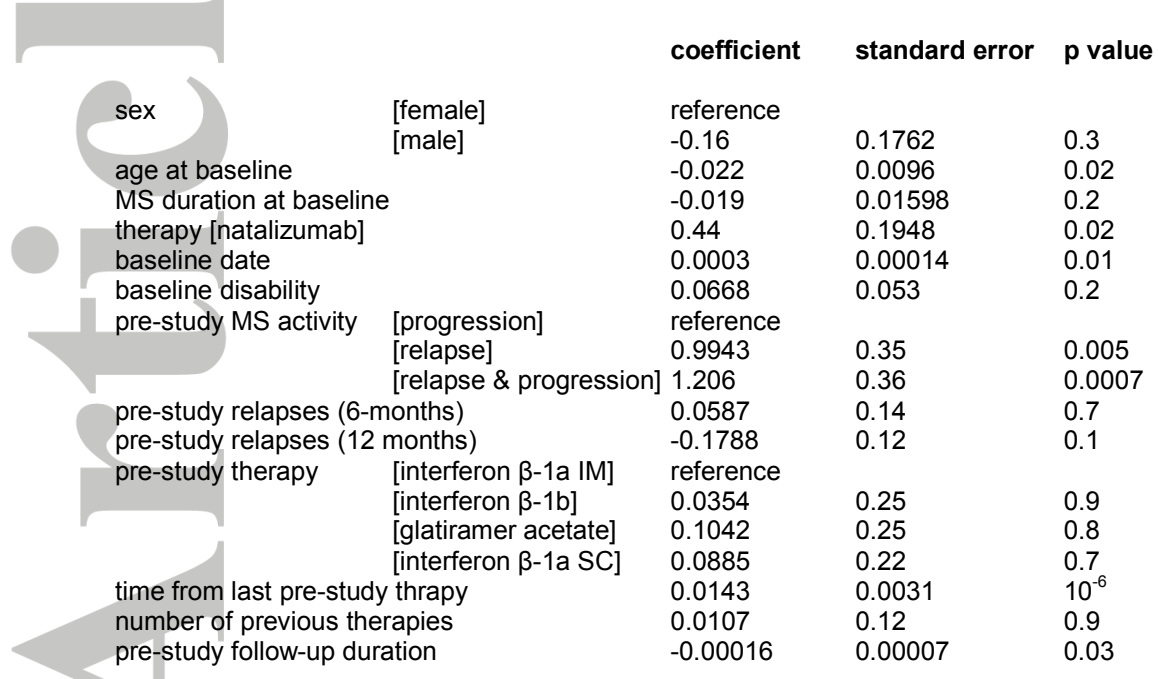

Outcome variable: indicator variable for the availability of baseline MRI information Model: multivariable logistic regression

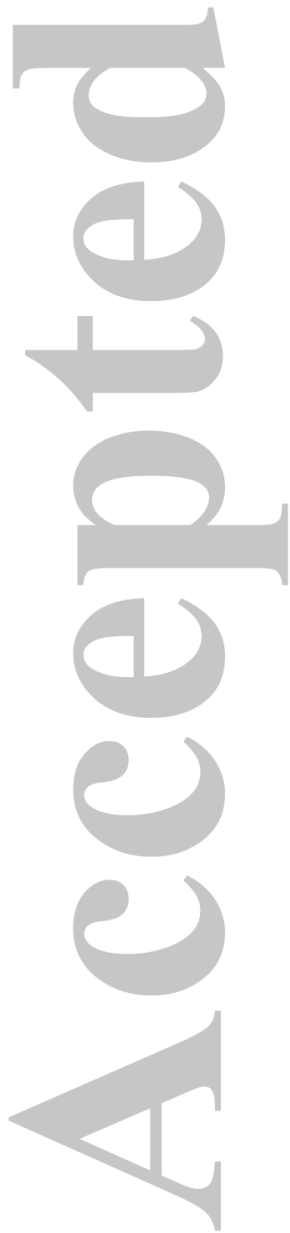

